\title{
On the toxicity of cellulose nanocrystals and nanofibrils in animal and cellular models
}

\author{
Célia Ventura • Fátima Pinto • Ana Filipa Lourenço • Paulo J. T. Ferreira • \\ Henriqueta Louro • Maria João Silva 10
}

Received: 10 December 2019/ Accepted: 20 April 2020

(C) Springer Nature B.V. 2020

\begin{abstract}
The need for reaching environmental sustainability encourages research on new cellulosebased materials for a broad range of applications across many sectors of industry. Cellulosic nanomaterials obtained from different sources and with different functionalization are being developed with the purpose of its use in many applications, in pure and composite forms, from consumer products to pharmaceutics and healthcare products. Based on previous knowledge about the possible adverse health effects of other nanomaterials with high aspect ratio and biopersistency in body fluids, e.g., carbon nanotubes, it is expected that the nanometric size of nanocellulose will increase its toxicity as compared to that of bulk
\end{abstract}

Célia Ventura and Fátima Pinto have contributed equally to this work.

C. Ventura $\cdot$ F. Pinto $\cdot$ H. Louro $\cdot$ M. J. Silva $(\bowtie)$

Department of Human Genetics, Instituto Nacional de

Saúde Dr. Ricardo Jorge, Av. Padre Cruz,

1649-016 Lisbon, Portugal

e-mail: m.joao.silva@insa.min-saude.pt

C. Ventura $\cdot$ H. Louro · M. J. Silva

NOVA Medical School, ToxOmics - Centre for

Toxicogenomics and Human Health, NOVA University of

Lisbon, Lisbon, Portugal

A. F. Lourenço · P. J. T. Ferreira

CIEPQPF, Department of Chemical Engineering, Pólo II,

University of Coimbra, Rua Silvo Lima, PT,

3030-790 Coimbra, Portugal cellulose. Several toxicological studies have been performed, in vitro or in vivo, with the aim of predicting the health effects caused by exposure to nanocellulose. Ultimately, their goal is to reduce the risk to humans associated with unintentional environmental or occupational exposure, and the design of safe nanocellulose materials to be used, e.g., as carriers for drug delivery or other biomedical applications, as in wound dressing materials. This review intends to identify the toxicological effects that are elicited by nanocelluloses produced through a topdown approach from vegetal biomass, namely, cellulose nanocrystals and nanofibrils, and relate them with the physicochemical characteristics of nanocellulose. For this purpose, the article provides: (i) a brief review of the types and applications of cellulose nanomaterials; (ii) a comprehensive review of the literature reporting their biological impact, alongside to their specific physicochemical characteristics, in order to draw conclusions about their effects on human health. 
Graphic abstract
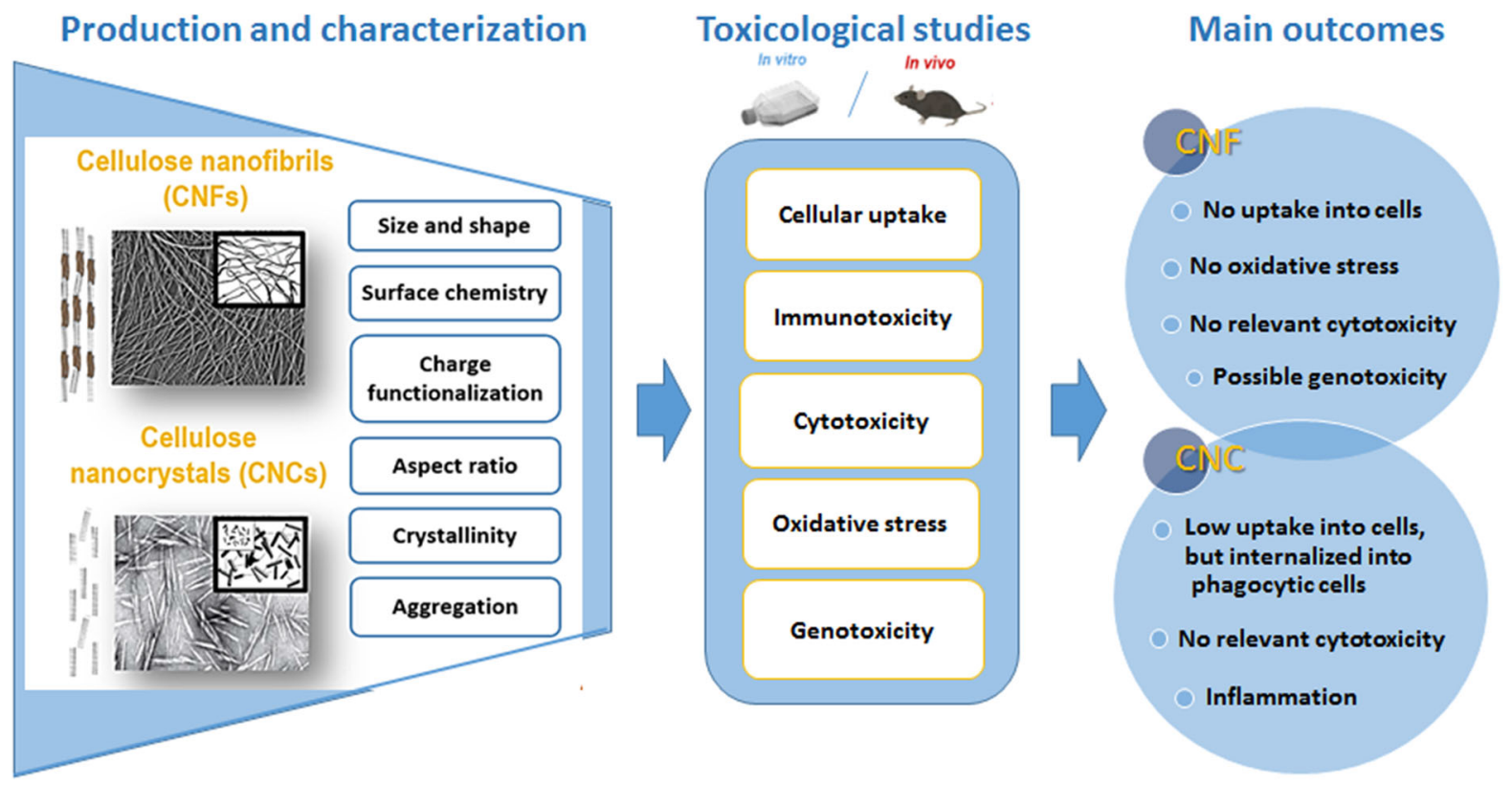

Keywords Cellulose nanocrystals - Cellulose nanofibrils · Nanocellulose production · Genotoxicity · Immunotoxicity $\cdot$ Nanotoxicology

\section{Abbreviations}

AC Algal cellulose

AFM Atomic force microscopy

ATP Adenosine triphosphate

BAL Bronchoalveolar lavage

BC Bacterial cellulose

CMF Cellulose microfibril

CNC Cellulose nanocrystal

CNF Cellulose nanofibril

CNM Cellulose nanomaterial

CNT Carbon nanotube

DEG Differentially expressed genes

DNA Deoxyribonucleic acid

FITC Fluorescein isothiocyanate

GCSF Granulocyte colony-stimulating factor

GSH Glutathione

IL Interleukin

INF- $\gamma \quad$ Interferon- $\gamma$

LDH Lactate dehydrogenase

LPS Lipopolysaccharide

NLPR3 NOD-like receptor pyrin domaincontaining 3

\begin{tabular}{|c|c|}
\hline NM & Nanomaterial \\
\hline MIP & Macrophage inflammatory protein \\
\hline MWCNT & Multi-walled carbon nanotube \\
\hline MTT & $\begin{array}{l}\text { 3-(4,5-Dimethylthiazol-2-yl)-2,5- } \\
\text { diphenyltetrazolium bromide }\end{array}$ \\
\hline OEL & Occupational exposure limits \\
\hline $\mathrm{OM}$ & Optical microscopy \\
\hline PBMNC & Peripheral blood mononuclear cells \\
\hline PDGF & Glioma-derived growth factor \\
\hline PMN & Polymorphonuclear neutrophils \\
\hline RANTES & $\begin{array}{l}\text { Regulated on activation, normal } \mathrm{T} \text { cell } \\
\text { expressed and secreted }\end{array}$ \\
\hline REL & Recommended exposure limits \\
\hline ROS & Reactive oxygen species \\
\hline SEM & Scanning electron microscopy \\
\hline $\mathrm{SH}$ & Protein sulfhydryl \\
\hline TEM & Transmission electron microscopy \\
\hline TEMPO & $\begin{array}{l}2,2,6,6-\text { Tetramethylpiperidine-1-oxyl } \\
\text { radical }\end{array}$ \\
\hline$N F-\alpha$ & Tumor necrosis factor $\alpha$ \\
\hline & Time-weighted average \\
\hline
\end{tabular}

\section{Introduction}

Due to its potential to improve many products and processes of interest to vital fields such as healthcare, 
energy, environment and manufacturing, the technology based on nanomaterials (NMs) has been pointed as a key enabling technology (European Commission 2009). Many products, already available, have materials in nanometric dimensions, such as silver, titanium dioxide or synthetic amorphous silica, and many other NMs are being developed, such as cellulose nanomaterials (CNMs). The global CNMs market is projected to grow to $€ 599.9$ million by 2023 , and thus, nanocellulose production will have a high economic impact (ResearchandMarkets, 2018). CNMs have diverse interesting applications in industry, including in papermaking, coatings, food, nanocomposite formulations and reinforcement, and potential for innovative biomedical applications, e.g., as drug delivery carriers, antimicrobial materials, and in tissue repair and regeneration (Lin and Dufresne 2014). Moreover, its expanding production and application can lead to unintentional human exposure, both for workers and consumers, and concerns about their potential effects on human health have emerged. A study by Vartiainen et al. (2011) concluded that worker's exposure to particles in the air during grinding and spray drying of birch cellulose is low or non-existent with the implementation of appropriate protection equipment and proper handling (Vartiainen et al. 2011). Another investigation found that nanocellulose is aerosolized during centrifugation, handling of dry product, and production and manipulation of nanocellulose polymer composites, but none of these measures exceeded the applicable occupational exposure limits (OEL) for cellulose (Eastlake et al. 2014; Martinez et al. 2013). The National Institute for Occupational Safety and Health (NIOSH) recommended exposure limits (REL) for bulk cellulose particles is $10 \mathrm{mg} / \mathrm{m}^{3}$ for total dust and $5 \mathrm{mg} / \mathrm{m}^{3}$ as a respirable fraction, both expressed as a time-weighted average (TWA). The Occupational Safety and Health Administration (OSHA) permissible exposure limits are $15 \mathrm{mg} / \mathrm{m}^{3}$ and $5 \mathrm{mg} / \mathrm{m}^{3}$, both as TWA. Currently, there are no OEL or REL for CNMs. However, based on previous knowledge about the adverse effects of other nanofibres, e.g., carbon nanotubes (CNT), it is expected that the high aspect ratio of some CNMs, such as cellulose nanofibrils (CNF), and its biopersistency in the lungs (Stefaniak et al. 2014) increases toxicity, as compared to that of bulk cellulose. Toxicological studies aim to generate data that contributes to predict the health effects from exposure to a given substance, as nanocellulose, thus allowing to reduce the risk to humans. To identify, in a short term, the toxicological properties of a substance, assays in mammalian cell lines (in vitro) or animal models (in vivo) are currently used (Fig. 1). The data obtained enables hazard identification, which complements exposure assessment through epidemiological studies in the framework of risk assessment. In vitro toxicological studies are typically conducted prior to in vivo studies to evaluate if the substance/material interacts with the cellular components or its functions, leading to an imbalance of cell homeostasis and to a measurable effect.

Conventional toxicological assays evaluate, among other endpoints, the effects of a substance on cell viability (cytotoxicity) leading to cell death generally through apoptosis or necrosis, and the direct or indirect damaging effects on DNA or chromosomes, such as gene mutations or chromosomal aberrations, respectively (genotoxicity) that can ultimately lead to carcinogenicity (Fig. 1). In fact, a major concern about the potential risks from human exposure to biopersistent nanofibres, as CNFs and CNTs, is whether they can be carcinogenic, since analogies have been established between the biological effects of CNT and the well-known carcinogenicity of asbestos (Kane et al. 2018). Another frequent outcome of persistent nanofibres is inflammation, an essential immune response to harmful stimuli, such as pathogens, tissues injury, toxicants or radiation, which enables survival during infection or damage and maintains tissue homeostasis (Fig. 2). A typical inflammatory response consists of four components: inflammatory inducers, the sensors that detect them, the inflammatory mediators induced by the sensors, and the target tissues that are affected by the inflammatory mediators (Medzhitov 2010). The persistence of the stimuli or deficiencies causing an excessive or subnormal inflammatory response may result in chronic inflammation (Nathan and Ding 2010), which is a major driver of disease, since it can irreversibly damage tissues and even lead to carcinogenesis through secondary genotoxic events mediated by oxidative stress. Thus, following an inflammatory process, cellular and molecular events take place to prevent inflammation perpetuation. Typically, the peak of the inflammatory response to aspirated fibrous particulates, including CNT and CNMs, is observed on days 1-7 and decrease after the first week postexposure (Park et al. 2018). 
Phagocytosis of nanofibres results in mitochondrial damage leading to the production of reactive oxygen species (ROS). ROS can induce a primary genotoxic effect, namely, DNA or chromosomal damage. ROS can also cause lysosome destabilization and consequent cathepsin B release that can further damage mitochondria. Furthermore, high aspect-ratio nanomaterials can also cause lysosomal rupture and release of cathepsin B to the cytosol. ROS generation leads to the oxidation of the redox-active thioredoxin (TXN) dissociating it from thioredoxin-interacting protein (TXNIP), and in its free form TXNIP can activate NLRP3 inflammasome. NLRP3 activation causes caspase-1 proteolysis of the precursor forms of cytokines IL-1 $\beta$ and IL-18 that in their active forms are powerful inducers of inflammation. The later produces ROS that can secondarily damage DNA (Adapted from Ventura et al. 2018b).
Among the assays available for investigating cellular and molecular effects, some have legal-binding status for regulatory purposes. Moreover, it has been proposed that an adequate risk analysis of NMs should incorporate their specific physicochemical properties into toxicological evaluation (European Parliament 2010), leading to an emergent area of toxicology designated as nanotoxicology. Accordingly, we have previously shown that NMs with the same chemistry, e.g., CNT and titanium dioxide NMs, but differing in primary properties may yield different biological effects (Louro et al. 2019; Tavares et al. 2014).

With the objective of identifying the toxicological effects that are elicited by CNMs produced from the vegetal biomass (top-down approach), either in vivo or in vitro, which potentially may lead to adverse health effects, this works describes: i) a brief review on the types and applications of CNMs; ii) a comprehensive review of the literature reporting their biological
In vitro

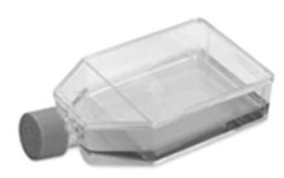

Culture of one or more cell types

(epithelial, endothelial, fibroblastic, osteoblastic, etc)

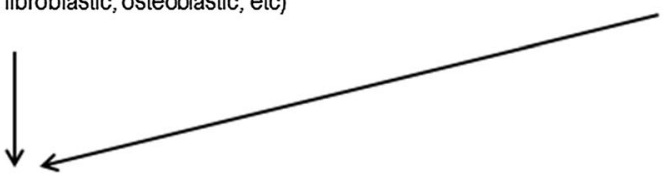

OBSERVABLE EFFECTS
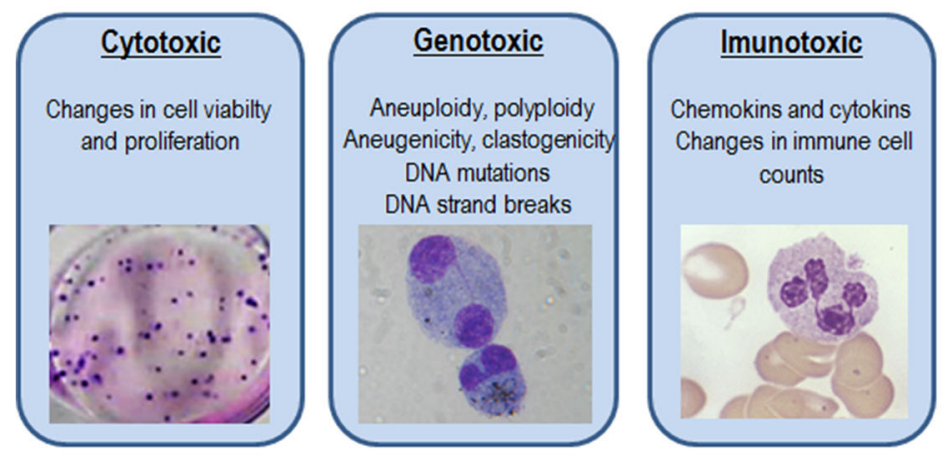

In vivo

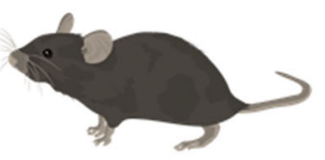

Organ and tissue extraction

(lung, heart, liver, blood, testis, etc)

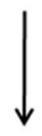

OBSERVABLE EFFECTS
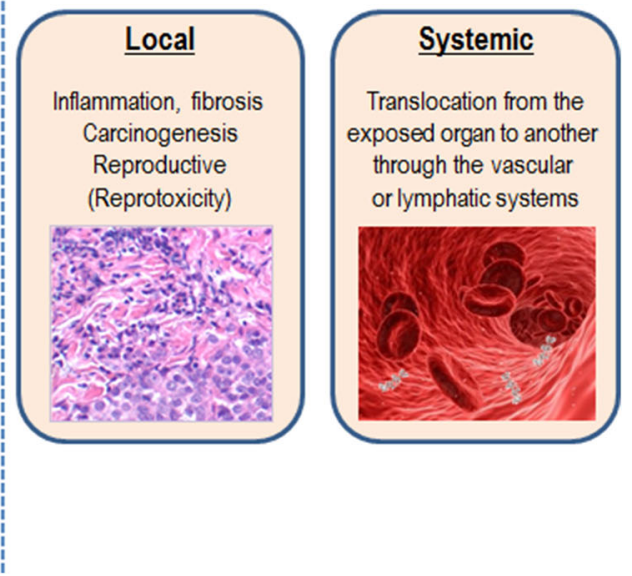

Fig. 1 In vitro and in vivo toxicological approaches to study the adverse effects of a substance or material, as CNMs. Adapted from (Ventura and Silva 2017) 


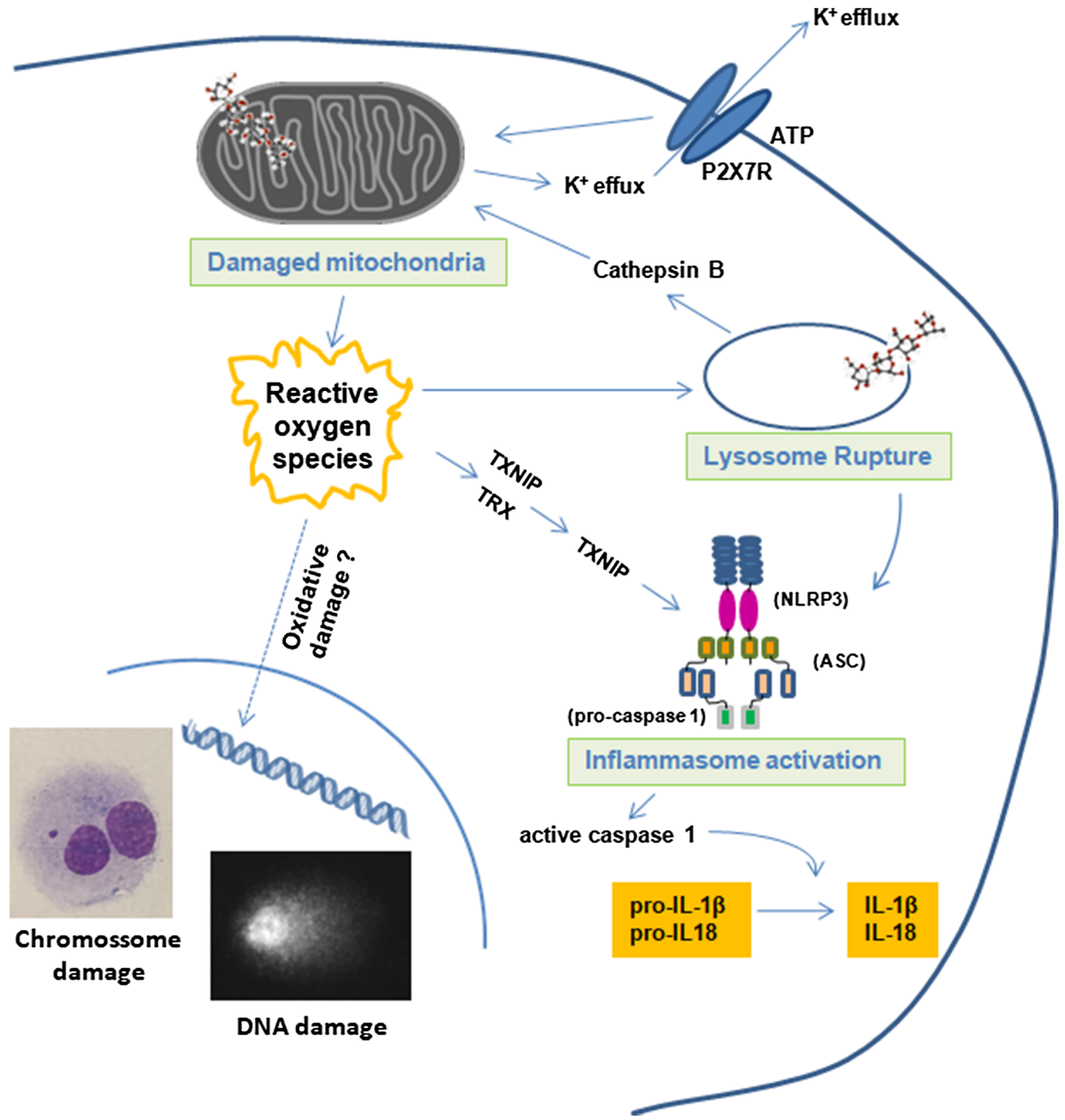

Fig. 2 Simplified representation of the mechanisms involved in activation of inflammation

impact, including cytotoxicity, oxidative stress, immunotoxicity, genotoxicity and reprotoxicity, alongside to their specific physicochemical characteristics. Based on the knowledge gathered through the literature review, the most relevant conclusions about the impact of these nanofibres on human health are presented.
Overview of nanocellulose production and applications

Nanocellulose is a natural nanomaterial that derives from cellulose, which can be extracted from abundant renewable biomass resources (Dufresne 2012a; Isogai and Zhou 2019). These cellulosic materials are described by having nano-sized widths (Dufresne 
2013; Nechyporchuk et al. 2016) and very promising properties such as excellent mechanical characteristics, chemical stability, biocompatibility and biodegradability (de Mesquita et al. 2010; Phanthong et al. 2018). These properties are mainly affected by the nanocellulose production process and the composition of biomass resulting in diverse cellulose nanomaterials (CNMs, nomenclature according to ISO/TS 20477: 2017 (ISO 2017)), with different morphologies, nanostructures and chemical structures (Isogai and Zhou 2019; Ribeiro et al. 2019).

Currently, there is high interest from academia and industry on technological discoveries and developments about nanocellulose, being its extraction from biomass and its possible applications in various fields commonly addressed (Phanthong et al. 2018; Ribeiro et al. 2019). There is a growing number of publications describing the preparation of various forms of nanocellulose such as suspensions, water-dispersible powders, films or nanopapers, hydrogels, and aerogels (Kargarzadeh et al. 2018) and their applications in hybrid composite materials (Islam et al. 2018), as drug delivery systems (Ching et al. 2019; Li et al. 2019), as food additives (Aaen et al. 2019; Alzate-Arbeláez et al. 2019), in biocompatible scaffolds for cell culture (Ojansivu et al. 2019; Or et al. 2019) and in tissue engineering (Luo et al. 2019; Zhao et al. 2019) among others.

Types of cellulose nanomaterials and production methods

Cellulose, as an ancient and important natural polymer, is the base for a new family of CNMs in the form of nanocellulose to be used in new applications that were once thought impossible for conventional cellulosic materials (Foster et al. 2018; Lin and Dufresne 2014).

Cellulose is a semi-crystalline polymeric material and encompasses a wide spectrum of nanoscale cellulosic-based structures existing in natural fibres having various shapes, sizes, surface chemistries and properties. CNMs can be isolated from a variety of sources as wood (hardwood and softwood), seed fibres (cotton, coir, etc.), grasses (bagasse, bamboo etc.), bast fibres (flax, hemp, jute, ramie etc.), marine animals (tunicate, sea squirt, etc.) and algae, or are generated by fungi, invertebrates and bacteria
(Kargarzadeh et al. 2018; Nechyporchuk et al. 2016; Varshney and Naithani 2011) (Fig. 3).

The resulting CNMs extracted from these broad raw material sources present different degrees of crystallinity, cellulose I polymorph (e.g., Ia/Ib ratio), particle aspect ratios, lengths, widths, and crosssection morphologies due to large differences in the cellulose biosynthesis processes (Foster et al. 2018). Regardless of its source, cellulose consists of a white fibre-like structure, chemically defined as a linear homopolysaccharide composed of $\beta$-D-glucopyranose units linked together by $\beta$-1-4-linkages, with no odor and a density of around $1.5 \mathrm{~g} / \mathrm{cm}^{3}$, which are predominantly located in the cell secondary wall and reinforce an amorphous matrix consisting of lignin, hemicellulose, proteins, extractive organic substances, and trace elements (Abdul Khalil et al. 2014; Kargarzadeh et al. 2018).

Individual cellulose molecules are assembled in biomass as elementary fibrils, which are packed into larger units labeled as microfibrils that, in turn, plug into fibres (Fengel and Wegener 1983). Elementary fibrils present a width of about $5 \mathrm{~nm}$ whereas the cellulose nanofibrils have widths ranging from 20 to $50 \mathrm{~nm}$ (Lavoine et al. 2012). Each elementary fibril can be considered as a flexible hair strand with highly ordered regions (i.e., crystalline), forming the core, which alternate with disordered domains (i.e., amorphous) that are present at the surface (Abdul Khalil et al. 2014; Azizi Samir et al. 2005; Shmulsky and Jones 2011) (Fig. 3).

CNMs were recently referred to be grouped into five broad categories, on the basis of (i) cellulose source, (ii) extraction/production method, and (iii) surface chemistry (Foster et al. 2018). Those categories comprise cellulose nanocrystals (CNCs), cellulose nanofibrils (CNFs), tunicate $\mathrm{CNCs}$ (t-CNCs), algal cellulose (AC), and bacterial cellulose (BC). While $\mathrm{CNCs}, \mathrm{CNFs}, \mathrm{t}-\mathrm{CNCs}$ and $\mathrm{AC}$ are produce by top-down procedures, the $\mathrm{BC}$ is synthesized with a bottom-up procedure from glucose by a family of bacteria, referred to as Gluconoacetobacter xylinus (Abdul Khalil et al. 2014; Klemm et al. 2011). In this review, the focus is on the two main types of nanocellulose, $\mathrm{CNCs}$ and $\mathrm{CNFs}$, which are produced from wood or agricultural/forest crops and residues.

The extraction of CNMs from wood and their derivatives generally consists of pre-treatment step(s) followed by mechanical step(s) (Brinchi et al. 


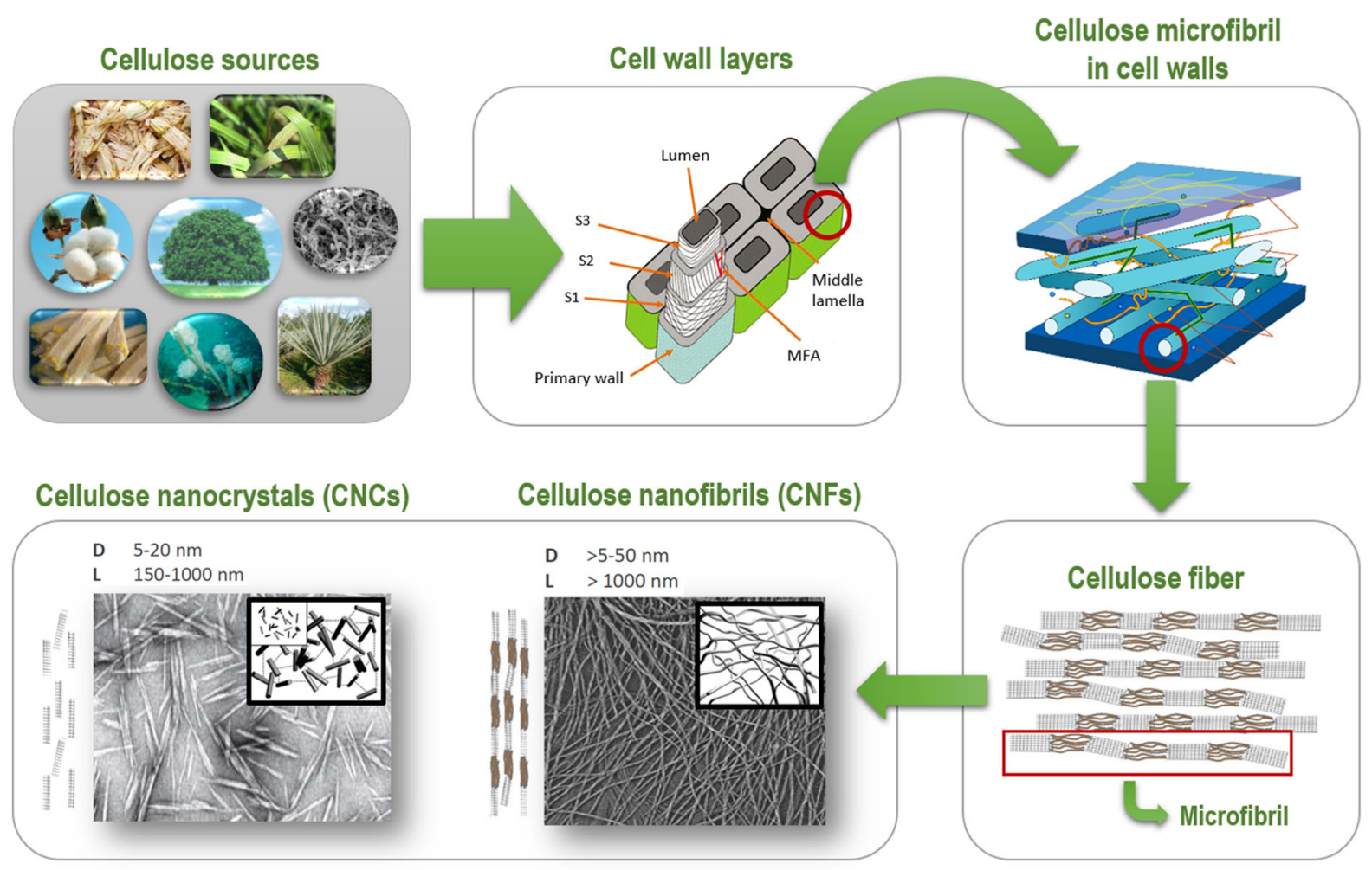

Fig. 3 Schematic illustration of cellulosic fibres hierarchical structure. From the cellulose source to the two types of nanocellulose materials (cellulose nanofibrils (CNFs), consisting on elementary fibril bundles of crystalline and amorphous

2013; Foster et al. 2018; Nechyporchuk et al. 2016). These production steps and their conditions will directly affect the properties of CNCs and CNFs, which major differences depend on the proportion of the amorphous phase and dimensions of the cellulose fibres (Kargarzadeh et al. 2018). The surface chemistry of nanocelulose is determinant in how these materials interact with their surrounding environment. The high chemical functionality of CNMs consist of primary and secondary hydroxyls on the surface, which may present other chemistries depending on the process used for their extraction (e.g., sulfate half ester, carboxylic acid, etc.) (Foster et al. 2018). These chemical functionalities provide a unique platform for relatively straightforward surface modifications (Habibi 2014) with bio-polymers and yield of cellulose derivatives by grafting to different materials, or by adding fluorescent tags, nanoparticles, etc. (Hubbe et al. 2015). regions and cellulose nanocrystals (CNCs), in the form of crystalline nanoparticles). Adapted from (Rol et al. 2019)

\section{Cellulose nanocrystals (CNCs)}

Throughout the years many terms were used to refer to cellulose nanocrystals (CNCs), e.g., cellulose whiskers, needles, nanocrystalline cellulose, rod-like colloidal particles or cellulose microcrystallites (Foster et al. 2018; Lavoine et al. 2012). CNCs derive from the crystalline regions within elementary nanofibrils of cellulose and are isolated from the cellulose amorphous domains of these nanofibrils (Bai et al. 2009; Beck-Candanedo et al. 2005; Garcia de Rodriguez et al. 2006) (Fig. 3). They exhibit a high degree of crystallinity (50-90\%) (Bras et al. 2011; Zhu et al. 2016) with limited flexibility compared to CNFs and present an elongated rod-like shape with a width of 3-50 nm, and length from $100 \mathrm{~nm}$ to several $\mu \mathrm{m}$ in length (ISO 2017). Both parameters are dependent on the cellulose source and extraction conditions (Abdul Khalil et al. 2014; Habibi et al. 2010; Kargarzadeh et al. 2018; Nechyporchuk et al. 2016). 
The most commonly used process for the extraction of CNCs from native cellulose is based on a strong acid hydrolysis under strictly controlled conditions of temperature, agitation, and time. Among various acids, hydrochloric and sulfuric acid have been extensively used in the extraction process (Roman and Winter 2004; Yu et al. 2013). In this procedure an acidic attack through transverse hydrolysis dissolve the amorphous portions (disordered regions) of cellulose, resulting in the formation of a nanocrystal structure (Kargarzadeh et al. 2018). During the acid hydrolysis, negatively charged sulfate groups will be introduced on the cellulose molecular chain due to the esterification of hydroxyl groups by sulfate ions, leading to intermolecular repulsive forces that confer electrostatic stability to $\mathrm{CNCs}$ in polar aqueous suspensions thus forming stable colloid systems (Das et al. 2009; Lu and Hsieh 2010; Roman and Winter 2004).

\section{Cellulose nanofibrils (CNFs)}

Cellulose nanofibrils (CNFs), also called nanofibrillated cellulose (NFC), microfibrillated cellulose (MFC), cellulose microfibrils (CMF), nanofibrils or microfibrils, are described as cellulosic nano-scale fibrils aggregates with high aspect ratio (Foster et al. 2018; Lavoine et al. 2012). The cross-section of CNF is in the range of 3 to $100 \mathrm{~nm}$ and its length is typically up to $100 \mu \mathrm{m}$ (ISO 2017), depending on the fibrils disintegration conditions, which are formed as a result of cellulose chain-stacking, induced by hydrogen bonds (Hoeng et al. 2016). It is not easy to determine the length of CNFs (commonly regarded as higher than $1 \mu \mathrm{m}$ ) using microscopy techniques. Therefore, only the information of the CNF fibril width is generally provided in the literature (Dufresne 2013).

CNFs are generally produced by a mechanically induced destructuring strategy for cellulosic pulp, for example, a high-pressure homogenizer (HPH) and/or grinding before and/or after a chemical or an enzymatic pre-treatment (Abdul Khalil et al. 2012; Kargarzadeh et al. 2018). The result of this high shear force process is a highly entangled network of nanofibrils with both crystalline and amorphous domains, which confers the morphology of CNFs with soft and long chains, by liberating the fibrils from the integral microfibre bundles (Fig. 3) (Habibi et al. 2010; Nechyporchuk et al. 2016; Turbak et al. 1983).
The production of CNFs through the mechanically disintegrated strategy, using different types of mechanical shearing actions that effectively delaminate individual nanofibrils from cellulosic fibres requires large amounts of energy ( $>200 \mathrm{kWh} / \mathrm{kg}$ ) (Isogai 2013; Isogai et al. 2011; Klemm et al. 2011). Thus, various mild pre-treatments for wood cellulose fibres before mechanical disintegration in water have been developed, such as alkaline ( $\mathrm{Lv}$ et al. 2010; Takács et al. 2000), radiation (Takács et al. 2000), chemical (Saito and Isogai 2004; Zhu et al. 2010), and enzymatic (Hayashi et al. 2005; Henriksson et al. 2007) approaches that remarkably lower the cost and energy of the process (Tayeb et al. 2018). This is a very important step as it can promote accessibility, increases the inner surface area, alters crystallinity, breaks hydrogen bonds, and boosts the reactivity of cellulose (Kargarzadeh et al. 2018; Mariano et al. 2014). Catalytic oxidation with 2,2,6,6-tetramethylpiperidine-1-oxyl radical (TEMPO) under aqueous conditions has been developed as a pre-treatment of plant cellulose fibres to efficiently prepare new nanocelluloses (Isogai et al. 2011; Saito et al. 2006; Zhou et al. 2018) while reducing the grinding cycles prior to the vigorous mechanical fibrillation by homogenization or microfuidization. This TEMPOmediated oxidation demonstrated to be advantageous in terms of reaction selectivity and efficiency, and proceeds at temperatures lower than conventional chemical reactions used for introducing carboxyl groups onto cellulose. Therefore, it can be regarded as a more sustainable chemistry route regarding energy consumption (Isogai and Bergström 2018). The resulting CNFs present a gel-like, shear thinning and thixotropic behaviour at low solid concentrations (1-2\%) in water, regardless of the production methods or pre-treatments used (Fang et al. 2014; Kang et al. 2015; Tayeb et al. 2018), which depend also of the cellulose source.

The biological process used for digesting or modifying cellulose fibres consists in enzymatic hydrolysis (Abdul Khalil et al. 2014). Although this pre-treatment is less aggressive than acid hydrolysis as it can be performed in mild conditions, it is more time consuming (Abdul Khalil et al. 2014; Moniruzzaman and Ono 2013; Phanthong et al. 2018). The enzymatic hydrolysis of cellulose occurs due to the synergistic effect of different enzymes, allied with mechanical treatments or acid reactants and allows the selective 
hydrolysis of non-crystalline cellulose, which facilitates its mechanical disintegration (Engström et al. 2006; Pääkkö et al. 2007). Moreover, through this environmental friendly pre-treatment it is possible to increase the extent of fine material, as compared to that of acid hydrolysis (Ribeiro et al. 2019). Thus, enzymatic pre-treatment seems to be a very promising method for industrial applications (Lavoine et al. 2012).

Properties and characterization of cellulose nanomaterials

Considering the heterogeneous nature of CNMs, the characterization of their physicochemical properties remains a challenge (Kangas et al. 2014). Nevertheless, a range of properties are particularly important for CNMs, such as their morphology, crystallinity, surface charge, surface chemistry, rheology, purity, mechanical properties, among others (Hoeger; Nechyporchuk et al. 2016) and there are several key methods typically used for the characterization of nanocelluloses (Ribeiro et al. 2019).

Similar morphologies with various dimensions are obtained depending upon the source of the cellulose and the method of production (Lavoine et al. 2012). Microscopy techniques can be employed for the analysis of morphology, which involves spatial resolution, orientation and distribution, and provides information about the size and shape of CNMs (Hoeger). Optical microscopy (OM) can be used for a general perspective of their aspect, morphology and size, and to evaluate the sample size/dimensions homogeneity (Pöhler et al. 2011; Saito et al. 2009). Nevertheless, higher resolution techniques, such as scanning electron microscopy (SEM), transmission electron microscopy (TEM) and atomic force microscopy (AFM) are the main approaches used to characterize the size of CNFs and CNCs, given that they provide details of their width and approximate length (Johansson et al. 2011; Pääkkö et al. 2007). SEM imaging has been used to provide a rough estimation of dispersion and distribution of nanocellulose, but in the case of CNF, the determination of length is difficult due to their entanglement and micrometer-scale (Kangas et al. 2014; Moon et al. 2013). TEM and AFM present higher resolution for evaluation of details on nanostructures morphology; although the preparation step of AFM is easier, the precision and resolution of images are not as good as those of TEM (Tsukamoto et al. 2013; Zhu et al. 2011).

The determination of surface charge and chemistry may be combined to follow the extent of chemical reaction on the surface of CNMs and to monitor the success of the chemical pre-treatment (Kangas et al. 2014). The surface chemistry of nanocelluloses dictates their colloidal stability, rheological and interfacial properties, and their interactions with other chemical species. Thus, it is crucial to determine whether $\mathrm{CNCs}$ are produced by acid hydrolysis or oxidation and by which reagents, or whether CNFs are TEMPO oxidized, carboxymethylated or have residual charge groups from hemicelluloses, etc. (Foster et al. 2018; Moon et al. 2011).

There is limited knowledge about the intrinsic mechanical properties of CNMs due to their nanometer size combined with limited metrology techniques available to characterize these organic materials (Moon et al. 2011). Existing experimental methods for the evaluation of moduli and tensile strength of nanocellulose include Wide-angle X-ray scattering (WAXS), Raman spectra (RS) and AFM (Cacciotti et al. 2014). For instance, the axial and transversal moduli of CNFs and CNCs can be experimentally determined by AFM (Isobe et al. 2011).

Rheological properties of CNMs depend on their structure, degree of dispersion, and interactions between the nanomaterial and the solvent or matrix in a composite system. Viscosity, or the resistance to flow, is very sensitive to changes in morphology and composition in a CNM system (Shafiei-Sabet et al. 2012). The characterization of CNMs rheology is commonly performed to establish relationships between production process, structure and consequent properties (Foster et al. 2018). Rheological measurements were also performed for CNFs prepared via TEMPO-oxidation and showed shear-thinning behavior following a power-law and thixotropic properties, which are explained through percolation in the fibrils and flock formation (Lasseuguette et al. 2008).

Different forms of cellulose nanomaterials and applications

The need for reaching environmental sustainability has been encouraging research on new cellulose-based materials for a broad range of applications across 
many sectors of the industry (Fig. 4), thus replacing conventional petroleum-based materials (Dufresne 2019; Tibolla et al. 2014). Nanocellulose, as a new environmental friendly material, has been incorporated into many types of materials, in both pure and composite forms and holds promise in many different applications, such as composite biomaterials (Sheikhi 2019; Shoseyov et al. 2019), in energy storage systems (Kim et al. 2019; Zhu et al. 2016), in gas field drilling and cementing applications (Balea et al. 2019; Ramasamy and Amanullah 2019), in textiles (Salah 2013), in functional packaging (Bras and Saini 2017), as drug delivery systems (Sheikhi et al. 2019) and in biomedicine (Gatenholm and Klemm 2010; Lin and Dufresne 2014; Zhang et al. 2019), in food industry, paper and boards, packaging, environmental protection and improvement, pharmaceuticals and healthcare (Abitbol et al. 2016; Gotta et al. 2018; Islam and Rahman 2019; Kargarzadeh et al. 2017; Pachuau 2017; Thomas et al. 2018). There are recent reviews reporting in further detail the applications of nanocelluloses (Abitbol et al. 2016; Grishkewich et al. 2017; Mondal 2017; Tayeb et al. 2018).

Nanocellulose, alone or in hybrid structures with additional polymers, can present a hydrogel form, which is defined as highly hydrated chemically or physically cross-linked network that can be fine-tuned by surface functionalization and self-assembly processes (Thomas et al. 2018). CNCs in water at a concentration higher than $10 \mathrm{wt} \%$ (Ureña-Benavides et al. 2011) and the hydrogel properties can be improved through chemical or physical modification with polymers. As an example, CNCs have been used to reinforce poly(vinyl alcohol) hydrogels (Han et al. 2014). At low cellulose concentrations, CNF suspensions appear as viscous fluids and can be converted into hydrogels holding a large amount of water, e.g., 99.9\%, while maintaining their shape (Saito et al. 2011). CNFs as longer and more flexible nanocelluloses are more amenable to hydrogels formation in their pure form and to produce more elastic gels than CNCs (Thomas et al. 2018). CNFs hydrogels have

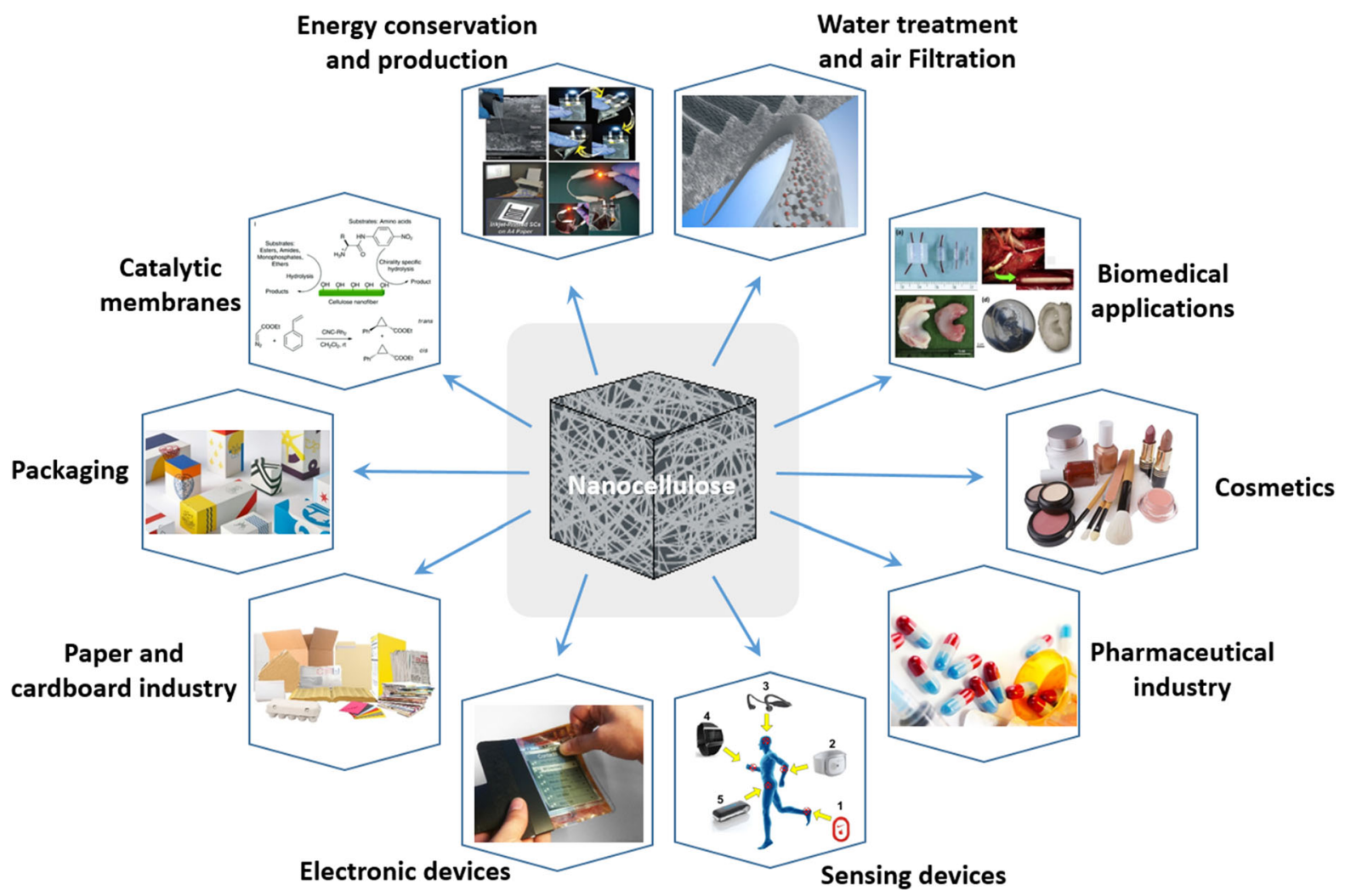

Fig. 4 State of the art of applications for new nanocellulose based materials. Adapted from (Barhoum et al. 2017; Thomas et al. 2018) 
been applied as starting materials to spin fibres with excellent strength properties (Lundahl et al. 2016).

Aerogels are the counterpart of hydrogels with gas in place of liquids, being highly porous and light materials. Porous sponge-like materials or CNF aerogels with high specific surface area, low density and high porosity can be obtained by preserving the CNFs three-dimensional (3D) network during dehydration (Nechyporchuk et al. 2016). In the same way, aerogels with high specific surface area and much improved mechanical resistance, compared with inorganic oxide based systems, can be obtained from CNCs due to their favorable mechanical properties (Yang and Cranston 2014).

$\mathrm{CNF}$ and $\mathrm{CNC}$ suspensions can be further converted to other forms, such as transparent films or powders and can be integrated into many different high-performance materials for customer and industrial applications (Barhoum et al. 2017). However, due to the high hydrophilic character and to the tendency to irreversibly aggregate while drying, one significant challenge is to produce dry CNF powder with a preserved nanoscale structure and re-suspension capacity, which would provide advantages in storage and transportation (Nechyporchuk et al. 2016).

\section{Toxicological studies on cellulose nanomaterials}

The toxicological properties of CNMs have been predominantly characterized in vitro, using mammalian cell lines that are exposed to increasing concentrations of the nanomaterial, for a defined period of time. Several endpoints related to cell death, activation of the immune response and inflammation, oxidative stress and genetic damage have been assessed. These endpoints, together with the physicochemical properties of the CNM and its internalization by cells, give important insights about the CNMs potential adverse effects and related mechanisms, in living organisms. However, these in vitro bioassays do not consider the complex and integrated response of a whole organism and do not allow a direct translation of the results into human health outcomes. Although the usage of in vivo studies has been restricted due to ethical concerns, they provide more valuable information about the toxicological properties and potential health effects that might be expected in man. As there are much more in vitro then in vivo studies on nanocellulose-biological systems interactions, and most of them is focused only on a specific nanocellulose type, the in vitro toxicological studies are first reviewed for each type of CNM considered, i.e., for CNCs, and for CNFs. The results of in vitro studies concerning $\mathrm{CNCs}$ and $\mathrm{CNFs}$ are summarized in Tables 1 and 2, respectively, while in vivo studies are summarized in Table 3.

In vitro studies

\section{Cellulose nanocrystals (CNCs)}

Cellular uptake Cellular uptake of CNCs has been examined in order to evaluate their potential as carriers for macromolecules (drugs, DNA, etc.) delivery or as part of toxicological studies. In view of their application as nanocarriers, two different studies showed that the level of FITC-labeled CNC uptake by different mammalian cell lines (epithelial, endothelial, fibroblasts and macrophages) was quite low (Roman et al. 2009; Dong et al. 2012). Similarly, using dark field hyperspectral imaging for bare CNCs and confocal microscopy for fluoresceinamineconjugated CNCs, Hosseinidoust et al. (2015) reported that only a very limited quantity of six different CNCs was uptaken by different cell lines, although a clear time- and dose-dependent internalization was found. As expected, macrophages exhibited an uptake capacity four-fold higher than the non-phagocytic cells. Since the cell membrane of macrophages was intact, their presence inside the cells indicated a mechanism of active or passive transport. Furthermore, the soft, amorphous and highly carboxylated $\mathrm{CNC}$ poles appeared to enhance their uptake, suggesting that the increase in transport of CNCs with a higher charge is mediated by an interaction of these carboxyl-rich chains with the cell membrane (Hosseinidoust et al. 2015). In the context of toxicological studies, Erden et al. (2019) observed murine alveolar MH-S macrophage uptake of a pristine $\mathrm{CNC}$, being $\mathrm{CNCs}$ in gel more internalized than in powder; the internalization possibly occurred through phagocytosis or macropinocytosis. A recent study, using spherical negatively charged FICT-labelled CNC derived from oil palm empty fruit bunch, revealed negligible cellular accumulation on either C6 rat glioma or NIH3T3 murine fibroblasts after 4 h exposure (Shazali 


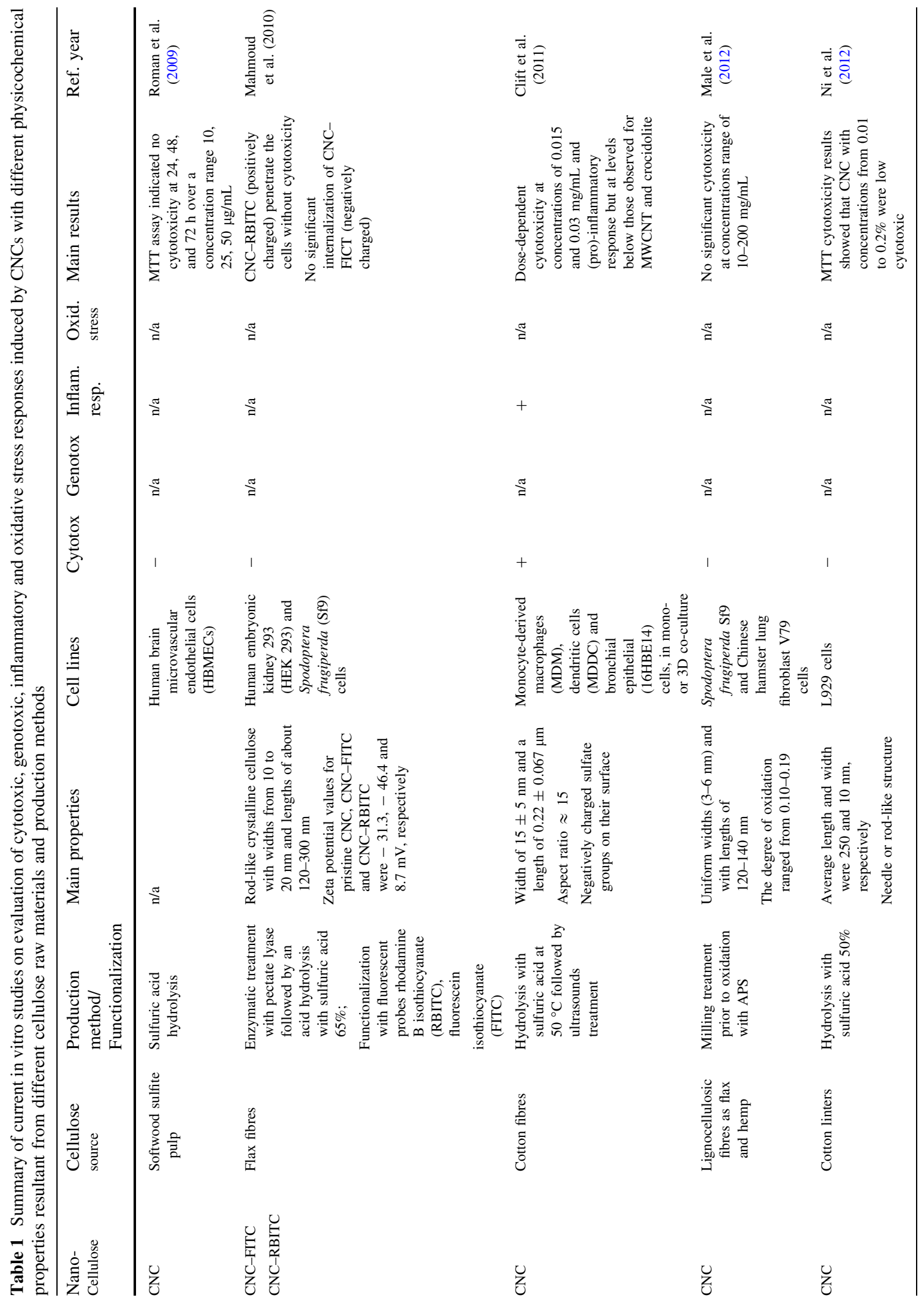




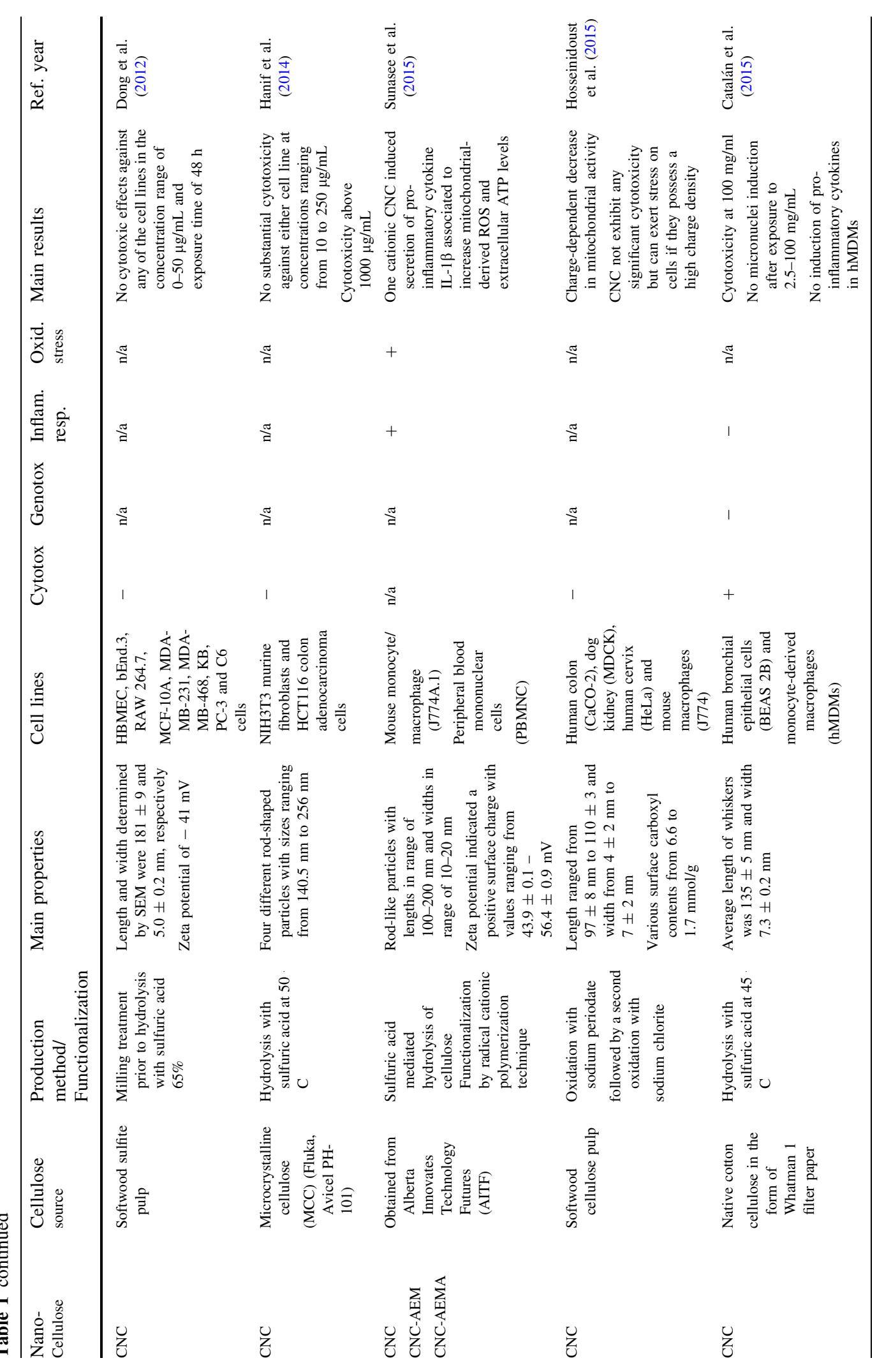




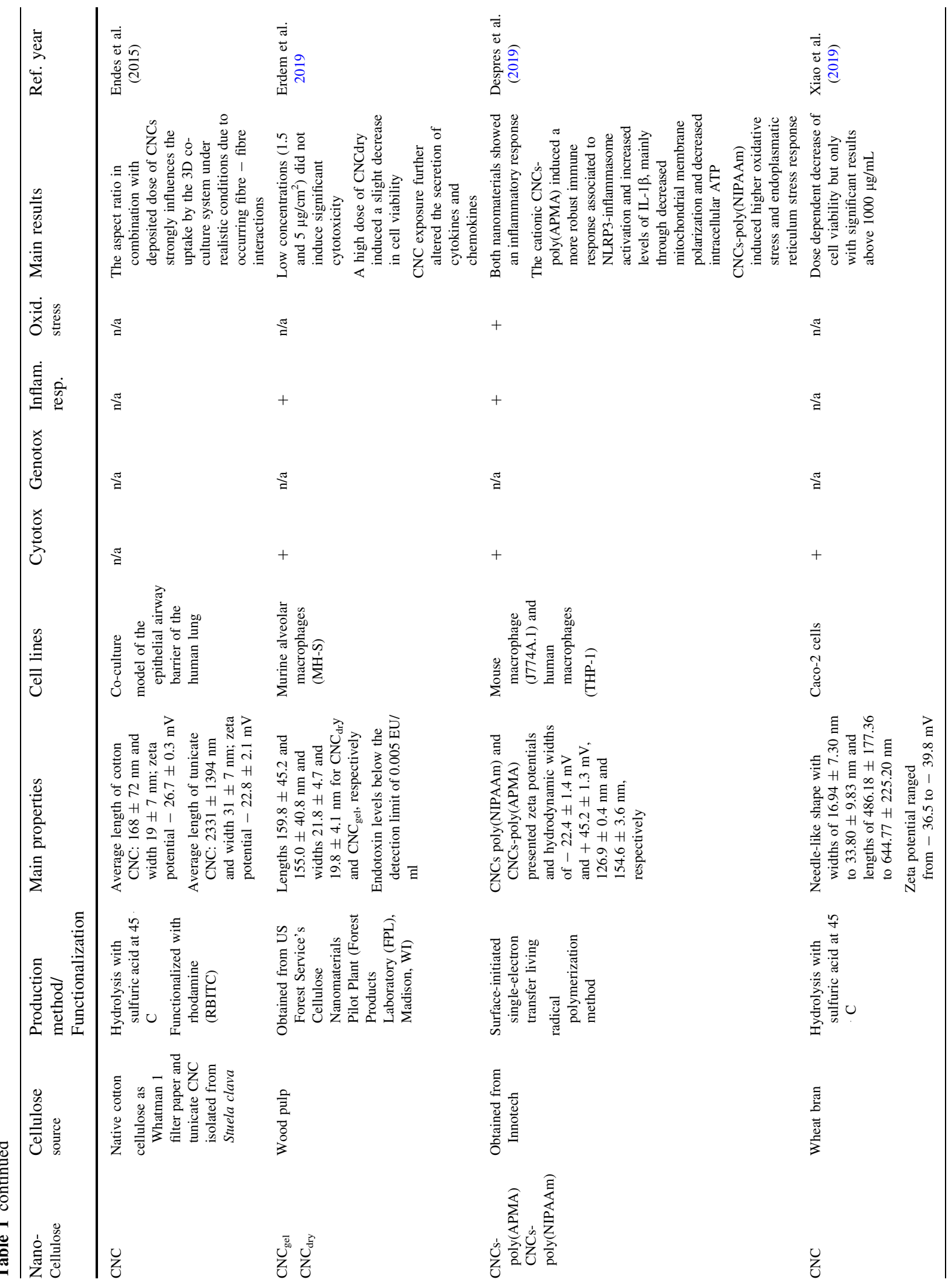




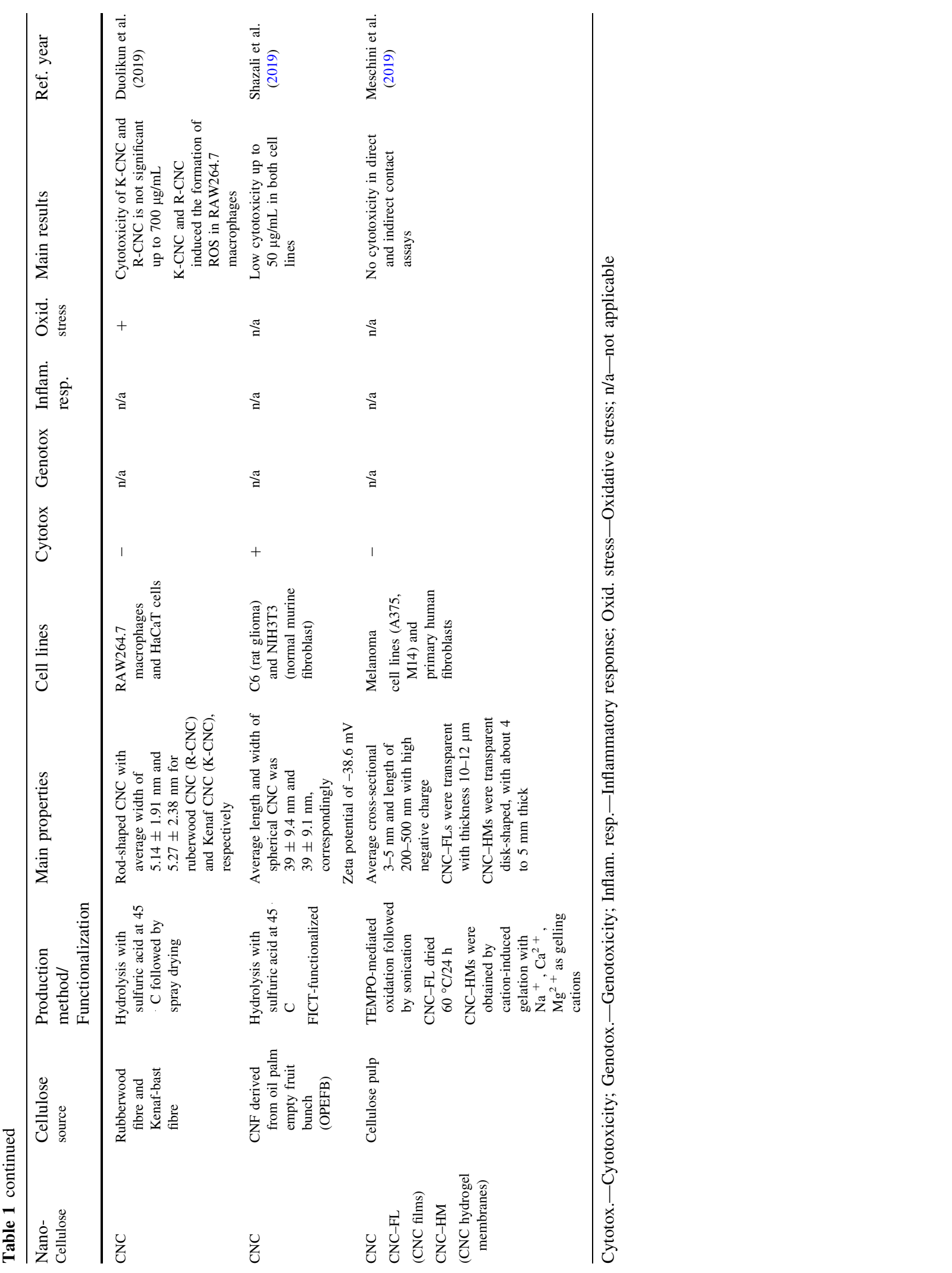




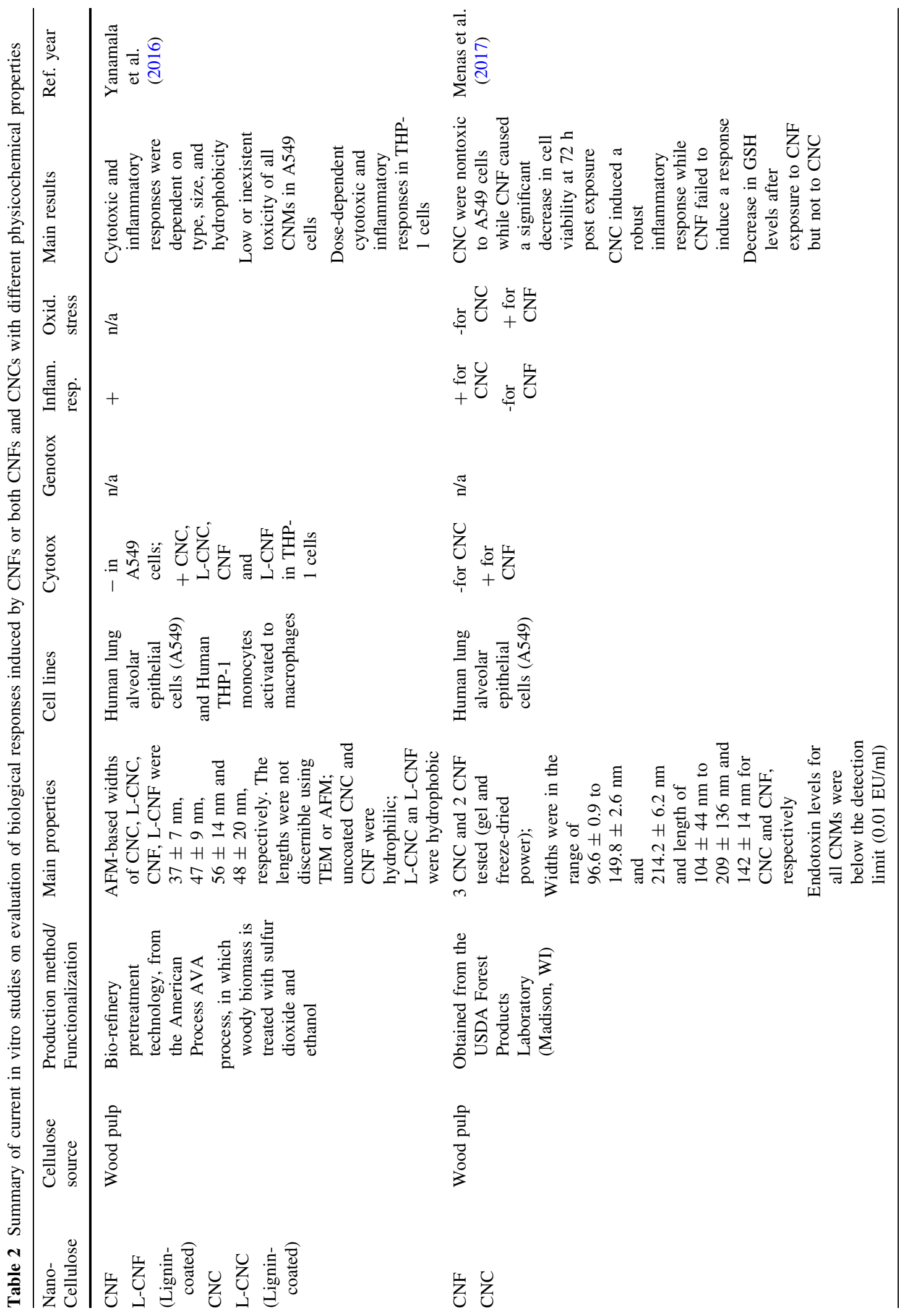




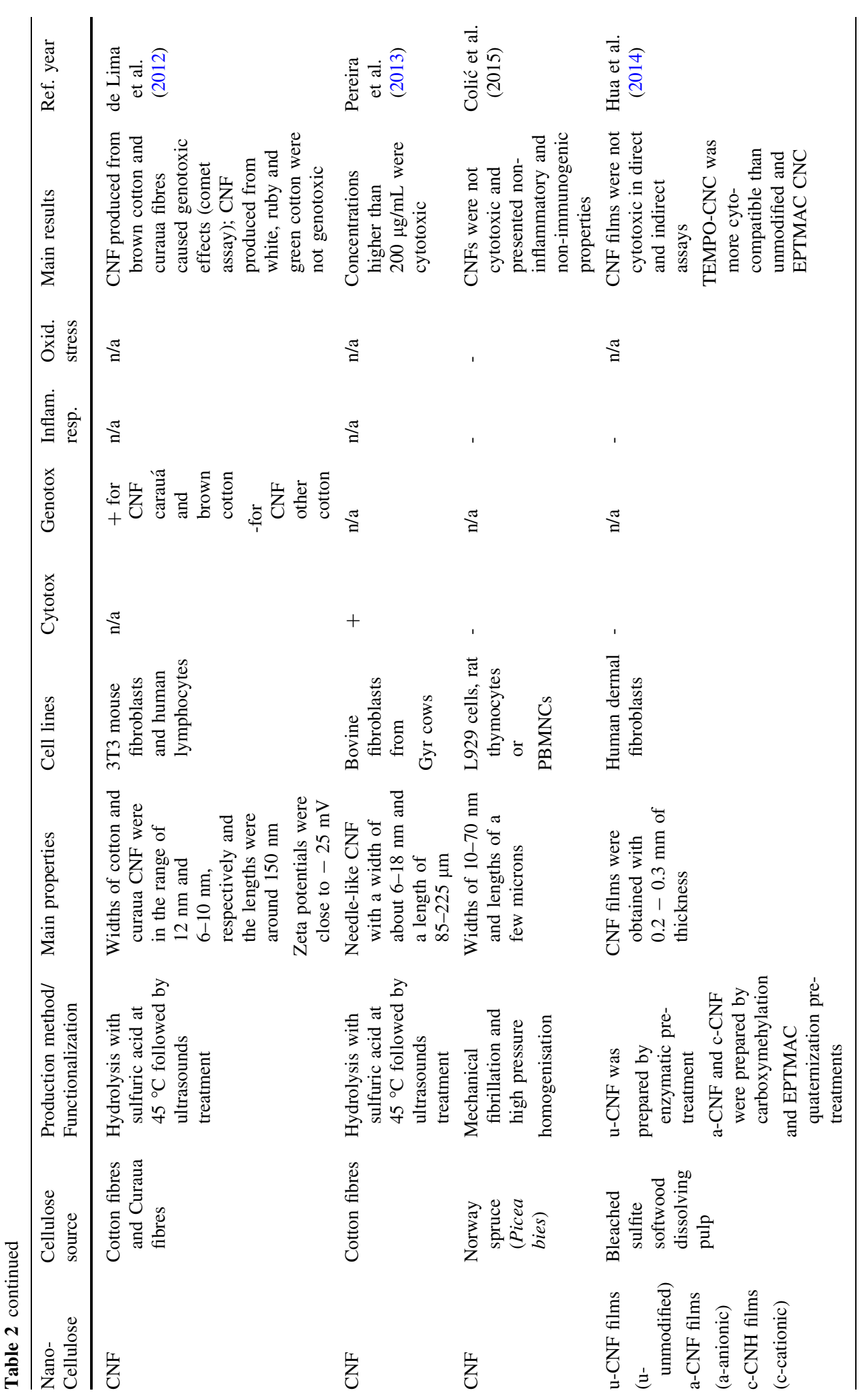


Cellulose

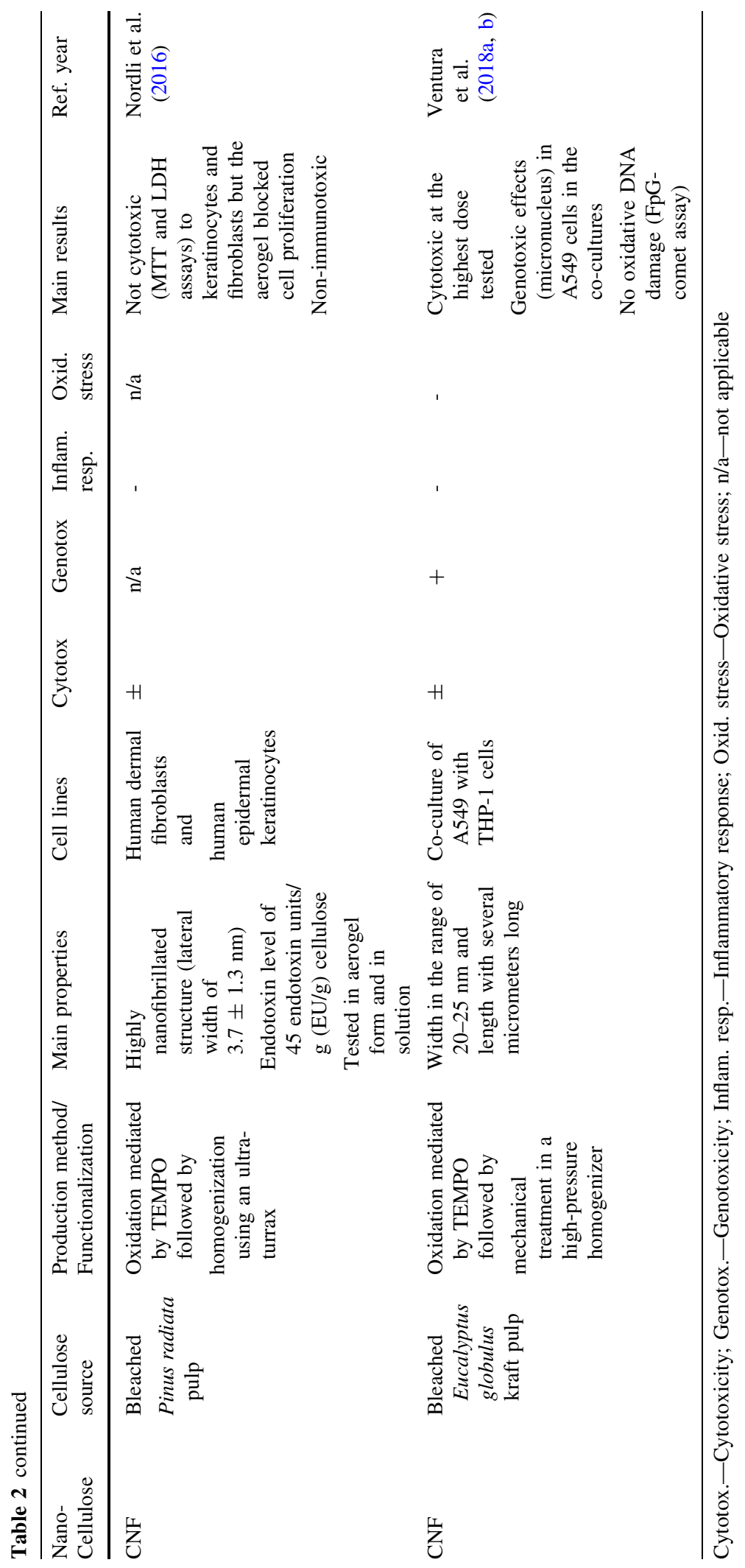

Springer 


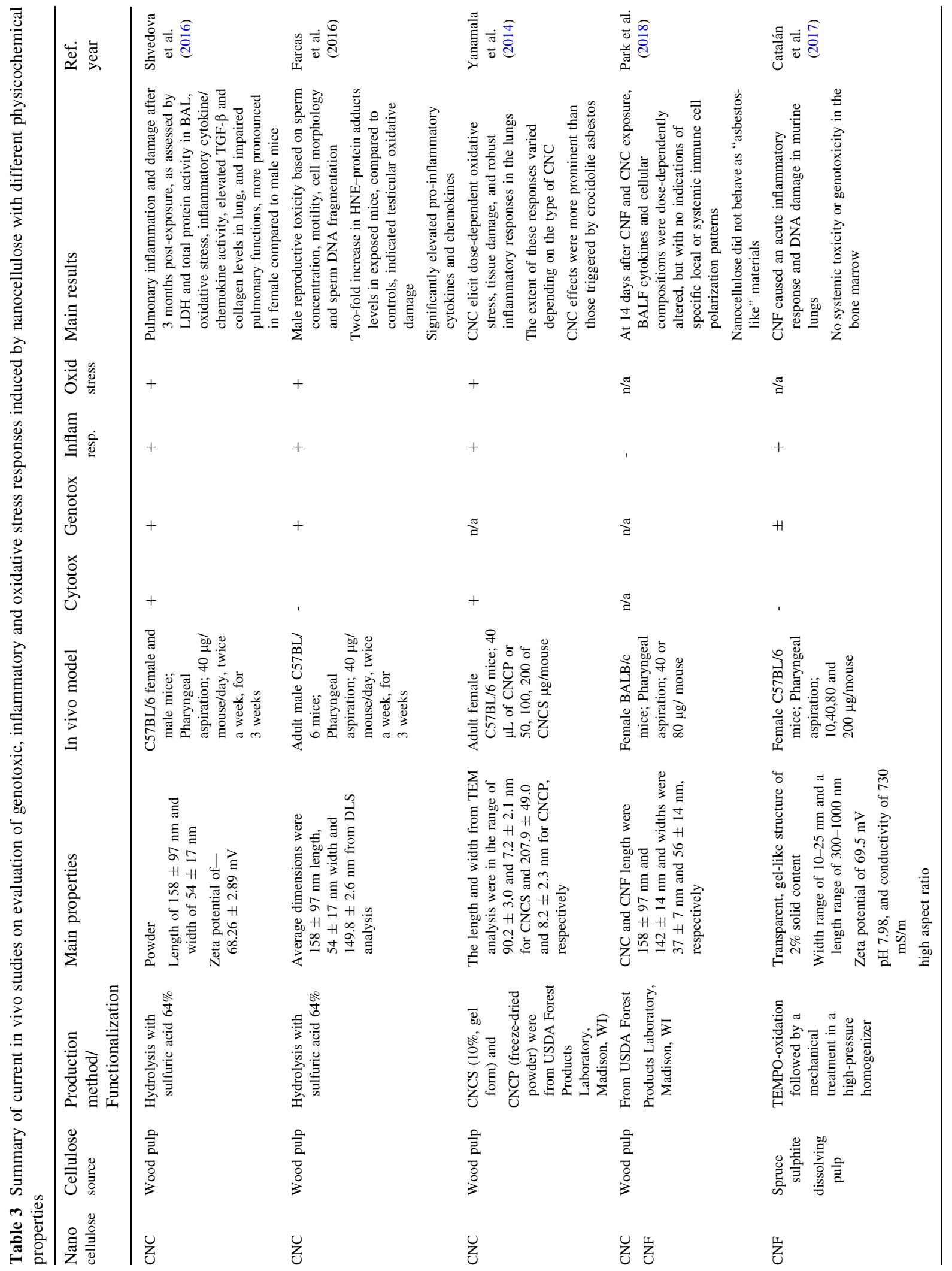




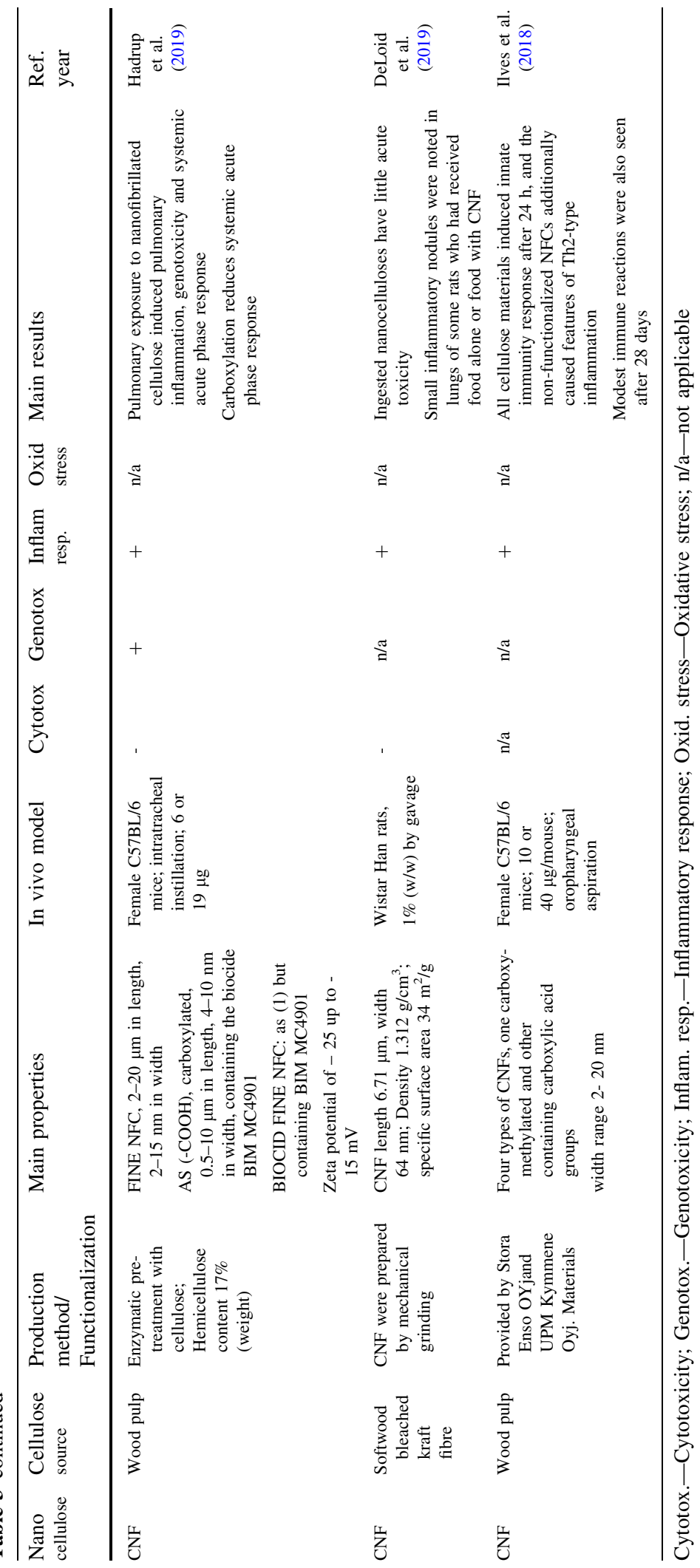


et al. 2019). Likewise, no CNC uptake was observed for human alveolar epithelial A549 cells (Menas et al. 2017). Endes et al. (2015) evaluated the specific fibrecell interactions of two CNCs, one isolated from cotton $(237 \pm 118 ; 29 \pm 13 \mathrm{~nm})$ and another from tunicate $(2244 \pm 1687 ; 30 \pm 8 \mathrm{~nm})$, with an in vitro multicellular model of lung epithelium using an airliquid interface cell exposure system. The interaction was dose-dependent, with the longer CNCs exhibiting a lower lung clearance as compared to the shorter $\mathrm{CNCs}$, since after $48 \mathrm{~h}$ they were still visible on the apical surface of the cell layer, while the short CNCs were engulfed by the macrophages and cleared from the cell surface within $24 \mathrm{~h}$ post exposure.

In summary, the internalization of $\mathrm{CNCs}$ and accumulation in cells occurs, although at a limited level. The uptake of these NMs is influenced by its size and surface properties, e.g., charge, and depends also on the cell type and function, being higher in macrophages than in epithelial cells.

Immunotoxicity Inflammasomes comprise a group of large intracellular multiprotein signalling complexes that respond to exogenous stimuli and control the proteolytic activation of interleukins, namely interleukin (IL)-1 $\beta$ and IL-18. It is believed that needle-like NMs, e.g. CNT, cause the activation of the NOD-like receptor pyrin domain-containing 3-(NLPR3)-inflammasome through reactive oxygen species (ROS) production, cathepsin B activity, P2X7 receptor, and Src/Syk tyrosine kinases, inducing IL-1 $\beta$ secretion (Palomaki et al. 2011). CNCs and CNFs display some characteristics similar to the ones described for asbestos fibres and CNTs, namely, their high-aspect ratio, insolubility and biopersistency and thus may also be able to activate the NLPR3-inflammasome or other inflammation pathways (Stefaniak et al. 2014). Other properties, e.g., surface charge or functionalization may also affect the ability of CNCs to active an immune response.

In fact, one cationic modified CNC $(50 \mu \mathrm{g} / \mathrm{mL}$, $24 \mathrm{~h}$ exposure) was able to increase IL- $1 \beta$ secretion in mouse macrophages (J774A.1) and in lipopolysaccharide (LPS)-primed and non-primed human peripheral blood mononuclear cells (PBMNC) (Sunasee et al. 2015). This increase in IL-1 $\beta$ correlated with the increase of mitochondrial ROS production and extracellular adenosine triphosphate (ATP) levels suggesting that it may be associated with its capability activate the NLRP3 inflammasome. However, the other cationic CNCs tested did not activate the NLRP3 /IL- $1 \beta$ inflammatory pathway. The difference between the CNCs was the molar ratio of monomers (aminoethylmethacrylate (AEM) or aminoethylmethacrylamide (AEMA)) to hydroglucose units, resulting in more or less cationic polymer brushes. In another study comparing cationic (poly(APMA)) and an anionic (poly(NIPAAm)) functionalized $\mathrm{CNCs}$, the cationic induced a more robust immune response associated to NLRP3-inflammasome activation and increased levels of IL- $1 \beta$ in murine macrophages, mainly through decreased mitochondrial membrane polarization and decreased intracellular ATP. The anionic CNC induced unspecific immunological effects, either NLRP3-dependent or independent, leading to greater amounts of mitochondrialderived ROS and an endoplasmatic reticulum stress response (Despres et al. 2019).

Concerning the CNC hydrophobicity, an uncoated hydrophilic CNCs elicited a more robust inflammatory response than its lignin-coated hydrophobic form (Yanamala et al. 2016). After $24 \mathrm{~h}$ exposure $(50 \mu \mathrm{g} /$ $\mathrm{mL}$ ) of human monocyte-derived macrophages (THP1 cells) to the uncoated $\mathrm{CNC}$, an increased level of cytokines and chemokines (IL-1 $\beta$, IL-2, IL-4, IL-6, IL-8, IL-9, IL-15, IL-17, granulocyte colony-stimulating factor (GCSF), interferon (INF) $\gamma$, eotaxin, macrophage inflammatory protein (MIP)- $1 \alpha$, MIP- $1 \beta$, regulated on activation, normal $\mathrm{T}$ cell expressed and secreted (RANTES), interferon $\gamma$-induced protein 10 (IP10) and tumor necrosis factor (TNF)- $\alpha$ ) was detected; the response was intensified upon $72 \mathrm{~h}$ exposure. Conversely, the hydrophobic CNC only increased the levels of five of those cytokines at $24 \mathrm{~h}$, and their levels were normal after $72 \mathrm{~h}$ exposure. In contrast, pristine, cotton-derived $\mathrm{CNCs}$ (average length $135 \pm 5 \mathrm{~nm}$; width $7.3 \pm 0.2 \mathrm{~nm}$ ), did not induce IL-1 $\beta$ and TNF- $\alpha$ in THP-1 cells after $6 \mathrm{~h}$ exposure $(30,100$, and $300 \mu \mathrm{g} / \mathrm{mL}$ ) (Catalán et al. 2015). Likewise, another study reported that pristine $\mathrm{CNC}$ was not able to induce macrophage polarization, and M0 macrophages expressed only low levels of cytokines and chemokines. However, macrophages polarized to M1 expressed high levels of IL-1 $\beta$ among other cytokines, and altered phagocytic activity following treatment with the same nanocellulose (Erdem et al. 2019). Regarding the size influence, 
three CNCs were with different sizes also induced a robust inflammatory response in A549 cells following $24 \mathrm{~h}$ and $72 \mathrm{~h}$ exposure, with a direct relationship between the size of the CNCs and the magnitude of response (Menas et al. 2017).

The various immune responses triggered by different $\mathrm{CNCs}$ (Table 1) highlight that differences in physicochemical characteristics (size, charge, etc.) are critical to their immunotoxicity and should be taken into account when considering biomedical applications or human exposure, e.g., through inhalation.

Cytotoxicity, oxidative damage and genotoxicity Due to the interest of researchers in finding the potential of CNCs as drug carriers, in chemotherapy or in patches, their cytotoxicity has been investigated in several publications using different cell lines and different functionalized CNCs. There was no evident loss of cell viability in human brain microvascular endothelial cells (HBMEC) exposed to 10,25 and $50 \mu \mathrm{g} / \mathrm{mL}$ CNCs for $24 \mathrm{~h}, 48 \mathrm{~h}$ and $72 \mathrm{~h}$ (Roman et al. 2009), in L929 cells (Ni et al. 2012), and in A549 cells exposed to 1.5, 15 and $40 \mu \mathrm{g} / \mathrm{cm}^{2}$ for $24 \mathrm{~h}$ and $72 \mathrm{~h}$ (Menas et al. 2017 ) or to $5-300 \mu \mathrm{g} / \mathrm{mL}$ for $24 \mathrm{~h}$ and $72 \mathrm{~h}$ (Yanamala et al. 2016). No cytotoxicity (MTT and $\mathrm{LDH}$ assays) was detected for a $0.05 \mathrm{wt} \% \mathrm{CNC}$ suspension $(0-50 \mu \mathrm{g} / \mathrm{mL}$ for $48 \mathrm{~h})$ tested in several human (endothelial and epithelial cells; HBMEC, MCF-10A, MDA-MB-231, MDA-MB-468, KB, PC-3 cells) and mouse cell lines (endothelial cells and macrophages; bEnd.3, RAW 264.7 cells) and in one rat fibroblast (C6) cell line (Dong et al. 2012). Only a slight cytotoxicity was observed in macrophages exposed to a pristine $\mathrm{CNCs}$, either in gel or in powder (Erdem et al. 2019). However, (Yanamala et al. 2016) observed a dose-dependent decrease in THP-1 cells viability after exposure to $5-300 \mu \mathrm{g} / \mathrm{mL}$ of hydrophilic (uncoated; width $37 \pm 7 \mathrm{~nm}$ ) or a hydrophobic (lignin-coated; $47 \pm 9 \mathrm{~nm}$ ) CNCs, more pronounced after $72 \mathrm{~h}$. A recent application of CNCs bearing negatively charged carboxylic groups in hydrogel membranes with $\mathrm{Na}^{+}, \mathrm{Ca}^{2+}, \mathrm{Mg}^{2+}$ as gelling cations was developed to use in active patches for photodynamic therapy of melanoma (Meschini et al. 2019). The cytotoxicity evaluation (MTT, morphological changes, organelles integrity) using two cell lines of melanoma and one cell line of human primary dermal fibroblasts exposed to the $\mathrm{CNC}$ membrane by direct and indirect contact tests demonstrated this hydrogel biocompatibility.

Negative results were also reported in another study that explored the potential of four CNCs of different sizes and shapes (mean sizes $256 \pm 64.8$ to $1174 \pm 338.7)$ to kill NIH3T3 murine embryo fibroblasts or HCT116 colon adenocarcinoma exposed to a concentration range from 10 to $250 \mu \mathrm{g} / \mathrm{mL}$ (Hanif et al. 2014), using the WST-1 assay; the authors noted that the larger one was toxic at high concentration because it formed a gel that probably blocked cells gas exchanges. Six different CNCs with different amounts of carboxyl groups, mostly located on amorphous carboxylated cellulose chains protruding from the CNC poles, were tested on the CaCO-2 (human colon epithelial), HeLa (human cervix epithelial), MDCK (canine kidney epithelial) and J774 (mouse ascites macrophage) cell lines over a wide range of concentrations (50-300 $\mu \mathrm{g} / \mathrm{mL}$ ) (Hosseinidoust et al. 2015). The authors reported a charge-dependent decrease in mitochondrial activity for charge contents higher than $3.9 \mathrm{mmol} / \mathrm{g}$. Conversely, all CNCs had a negligible effect on cell membrane integrity, except the CNCs with the highest charge density that were toxic at a high concentration. The cytotoxicity of cotton CNC (average length $135 \pm 5 \mathrm{~nm}$; width $7.3 \pm 0.2 \mathrm{~nm}$ ) was also evaluated in human bronchial epithelial BEAS-2B cells exposed to a concentration range of 15-300 $\mu \mathrm{g} / \mathrm{mL}$ for $4 \mathrm{~h}, 24 \mathrm{~h}$, and $48 \mathrm{~h}$ (Catalán et al. 2015). The concentration that resulted in $55 \pm 5 \%$ cell death was approximately $100 \mu \mathrm{g} / \mathrm{mL}$.

Furthermore, considering the widespread use of cellulose in food industry and its possible substitution by nanocellulose, DeLoid et al. (2019) evaluated the in vitro cytotoxicity of $\mathrm{CNCs}$ (and $\mathrm{CNFs}$ ) as a complement to in vivo endpoints that will be mentioned below. To assess the effects of ingested CNC in the gastrointestinal tract, a tri-culture model of small intestinal epithelium (CaCO-2, HT29-MTX and Raji $\mathrm{B}$ cells) was exposed to $\mathrm{CNC}$ (mean width $27 \mathrm{~nm}$ ) after simulating the in vitro digestion. After $24 \mathrm{~h}$ incubation with the digestion products, there was no changes in cytotoxicity (LDH) or in the monolayer integrity (trans-epithelial electrical resistance).

No significant cytotoxicity has been reported for CNCs tested in other cell models, as the S/9 insect cells and V79 Chinese hamster lung fibroblasts (Male et al. 2012), L929 mouse fibroblasts (Ni et al. 2012), C6 rat glioma and NIH373 murine fibroblasts (Shazali 
et al. 2019). New forms of rod-shaped CNCs have been produced from other vegetal biomass sources, as raw rubberwood and Kenaf-bast fibre (Tuerxun et al. 2019), and raw wheat bran (Xiao et al. 2019), and all these CNCs were tested by the MTT assay. The results showed the capacity of these CNCs to induce cell death but at very high concentrations, only. In the first study, a dose-dependent loss of cell viability upon exposure to macrophages (RAW 264.7) and HaCaT cells was observed, but without toxicity up to $700 \mu \mathrm{g} /$ $\mathrm{mL}$ (Tuerxun et al. 2019). In the last one, a dose dependent decrease of cell viability was also observed in CaCO- 2 cells but only with significant results above $1000 \mu \mathrm{g} / \mathrm{mL}$ (Xiao et al. 2019).

In respect to oxidative stress induction, no significant decrease in glutathione (GSH) levels, a marker of oxidative stress, was detected in A549 cells exposed to three different CNCs (Menas et al. 2017). Nitric oxide production by RAW264.7 murine cells was one of the endpoints tested in the Tuerxun et al. (2019) investigation on the new CNCs from rubberwood and Kenafbast fibres and there was almost a four-fold increase in the concentration of nitrite in macrophages, which correlated with their viability loss (Tuerxun et al. 2019). Lower concentrations of CNCs were considered non-toxic, as the level of induced nitrite was similar to the one induced by LPS (Tuerxun et al. 2019). ROS production was also assessed in DeLoid et al. (2019) study of digested CNC, and a small increase of ROS production was observed with CNCs at $1.5 \% \mathrm{w} / \mathrm{w}$, but when this CNCs was dispersed in a standardized food matrix the effect was no longer seen (DeLoid et al. 2019).

To the best of our knowledge, only one study has investigated the genotoxicity of CNCs (Catalán et al. 2015). Human bronchial epithelial BEAS-2B cells were exposed to cotton $\mathrm{CNCs}$ (average length $135 \pm 5 \mathrm{~nm}$; width $7.3 \pm 0.2 \mathrm{~nm}$ ) in a concentration range of $2.5-100 \mu \mathrm{g} / \mathrm{mL}$, and chromosomal damage was evaluated by the micronucleus assay yielding negative results.

Taken together, the great majority of studies addressing the potential of a vast diversity of CNCs from different origins and with diverse properties to cause cell death point to the absence of significant cytotoxic effects and a number of mammalian cell lines. Nevertheless, some cytotoxic effects were observed, either at very high concentrations that are unlikely to be reached in the organism or in particularly sensitive cells, such as macrophages. Again, properties like surface charge are important determinants to consider when producing new CNCs, especially for biomedical applications.

As already referred, the in vitro toxicological studies of CNCs are summarized in Table 1.

\section{Cellulose nanofibrils (CNFs)}

Cellular uptake Menas et al. (2017) used a specific staining method to visualize CNFs in A549 cells after $72 \mathrm{~h}$ exposure and found that the nanofibres were mainly localized at the cell boundaries, without the presence of CNFs inside the cells (Menas et al. 2017). Similarly, TEM analysis demonstrated no alterations in cell morphology and no uptake of any of the three different CNFs tested in THP-1 cells, which showed no attempts of phagocytosis (Lopes et al. 2017).

Immunotoxicity Colic et al. (2012) described no inflammatory and immunogenic properties of CNFs (width $10-70 \mathrm{~nm}$ ) in rat thymocytes and PBMNC. A panel of 27 cytokines, chemokines, and growth factors was tested in the Nordli et al. (2016) study of human dermal fibroblasts or epidermal keratinocytes exposed to an ultrapure TEMPO-mediated oxidized CNF, either in solution $(50 \mu \mathrm{g} / \mathrm{mL})$ or in an aerogel form (Nordli et al. 2016). All results were negative, indicating the absence of immunotoxicity and suggesting the potential of this CNF for use as a wound dressing-material. Similar results were obtained for a gel or freeze-dried CNF powder tested in A549 cells exposed to for $24 \mathrm{~h}$ and $72 \mathrm{~h}$, by the same immune response panel (Menas et al. 2017). This immunoassay was also applied to A549 and THP-1 cells exposed to a hydrophilic (uncoated) and hydrophobic (lignin-coated) CNF (Yanamala et al. 2016). A significant increase in IL-1 $\beta$, MIP- $1 \alpha$, MIP$1 \beta$, IL-6 and IL-15 was observed in THP-1 cells treated with $50 \mu \mathrm{g} / \mathrm{mL}$ of the hydrophilic CNFs for $24 \mathrm{~h}$, an effect that was absent at $72 \mathrm{~h}$ post exposure. The same concentration of the hydrophobic CNFs was able to increase the levels of IL-1 $\beta$, IL-2, IL-4, IL-6, IL-8, IL-9, IL-15, IL-17, GCSF, IFN- $\gamma$, eotaxin, MIP$1 \alpha$, MIP- $1 \beta$, and TNF- $\alpha$ in THP- 1 cells at $24 \mathrm{~h}$, with an additional increase in IL-1R $\alpha$, IL-10, IL-13, and glioma-derived growth factor (PDGF)-BB at $72 \mathrm{~h}$ exposure. In contrast, A549 cells did not show any difference after exposure. Likewise, no induction of 
IL-1 $\beta$ was detected in a co-culture of A549 cells and THP-1 cells exposed to three concentrations of CNFs produced by TEMPO-mediated oxidation of an industrial bleached Eucalyptus globulus kraft pulp (Ventura et al. 2018a). No immunotoxicity (TNF- $\alpha$, IL-1 $\beta$, IL-6, IL-10, MIP-1 $\alpha$ and IL-12p40) was observed in mouse RAW 264.7 macrophages after exposure (30, 100 and $300 \mu \mathrm{g} / \mathrm{mL}$ ) to a nonfunctionalized CNFs (median width 20-30 nm) (Vartiainen et al. 2011). On the contrary, a significant increase in TNF- $\alpha$ and IL- $1 \beta$ was observed in THP-1 cells after $24 \mathrm{~h}$ exposure $(500 \mu \mathrm{g} / \mathrm{mL})$ to CNFs produced from a bleached sulphite softwood dissolving pulp. However, these CNFs did not induce secretion of these two pro-inflammatory cytokines after surface modification to carboxymethylated-CNF and hydroxypropyltrimethylammonium-CNFs, underlining the relevance of surface chemistry in the inflammatory response (Lopes et al. 2017). Ilves et al. (2018) showed that among three different CNFs produced through an enzymatic pre-treatment, only the non-functionalized one, with the shortest width (2-15) and slightly negative zeta potential was associated to a timedependent increase of IL-1 $\beta$ and TNF, and to cell death (Ilves et al. 2018).

Comparably to what was observed for CNCs, a consistent immunotoxic effect (or its absence) has not been found for CNFs, with studies reporting positive or negative results in several cell lines. This is not unexpected given that these nanofibrils interaction with cells are largely dependent of their primary physicochemical properties and possible modifications that happen after their dispersion in the cells culture medium, as well as of the capacity of the cells, themselves, to uptake the CNFs.

Cytotoxicity, oxidative damage and genotoxicity Cytotoxicity assessment has been used to screen the CNF biocompatibility, and data is already available for several pristine and functionalized CNFs. Considering the existing concern about the resemblance of CNFs with other high-aspect ratio nanofibres that pose long-term risks to human health following inhalation, a study by Clift et al. (2011) compared the cytotoxic and inflammatory effects of CNFs isolated from cotton (length $0.22 \pm 0.07 \mu \mathrm{m}$; width $15 \pm 5 \mathrm{~nm}$ ) with those of a multi-walled carbon nanotube (MWCNT) and crocidolite fibres. Three different human cell types were used, namely monocyte-derived macrophages (MDM), dendritic cells (MDDC) and bronchial epithelial (16HBE14) cells, as well as a 3D co-culture of these cells to better mimic the airway wall of the human lung. CNF induced a dose-dependent citotoxicity (LDH assay) after 24 h exposure, but at levels below those observed for the MWCNT and crocidolite. The similarity of CNFs to CNTs was also emphasized by Menas et al. (2017) that compared five types of nanocellulose, including CNF powder in gel ( $0.9 \%$ wt.) and a freezedried CNF powder $(1.5,15$ and $45 \mu \mathrm{g} \mathrm{CNF}$ for $24 \mathrm{~h}$ and $72 \mathrm{~h}$ ) in A549 cells (Menas et al. 2017). Both CNFs decreased cell viability (Trypan blue exclusion assay), more significantly after $72 \mathrm{~h}$ (40-50\%), as compared to $24 \mathrm{~h}(10-20 \%)$. No cytotoxicity and oxidative stress was observed in L929 cells exposed to $31.25 \mu \mathrm{g} / \mathrm{mL}$ to $1 \mathrm{mg} / \mathrm{mL}$ CNFs, but a slight proliferation reduction occurred at concentrations above $250 \mu \mathrm{g} / \mathrm{mL}$ (Colic et al. 2015). Moreover, no necrosis and apoptosis was observed in rat thymocytes and human PBMNC. A study performed by Ventura et al. (2018a) also found no cytotoxic effects (MTT and LDH assays) in A549 cells after $24 \mathrm{~h}$ exposure $\left(1.5,3,6,12.5\right.$, and $\left.25 \mu \mathrm{g} / \mathrm{cm}^{2}\right)$ to $\mathrm{CNFs}$ produced by TEMPO-mediated oxidation pre-treatment, but the highest dose tested was cytotoxic after $48 \mathrm{~h}$ exposure (Ventura et al. 2018a). Interestingly, at this exposure period, the lowest CNF concentration resulted in a significant increase in cell viability (MTT assay) while a more prolonged (8 days) exposure stimulated cells proliferation and their capacity to form colonies (clonogenic assay). Lopes et al. (2017) studied the cytotoxicity of CNFs with two different surface modifications, carboxymethylated-CNF and hydroxypropyltrimethylammonium-CNFs, and its unmodified counterpart, produced from a bleached sulphite softwood dissolving pulp, using human lung fibroblast (MRC-5) cells, THP-1 macrophages and human dermal fibroblasts (HDF) (Lopes et al. 2017). No cytotoxicity (Alamar blue and LDH) was detected for the HDF and MRC-5 cells following treatment with a concentration range of each CNF for $24 \mathrm{~h}$; THP-1 cells showed an increase in their metabolic activity in line with the observation by Ventura et al. (2018a). Amongst the bulk-sized cellulose and the four different CNFs under study by Ilves et al. (2018), only one non-functionalized CNFs reduced cell viability (LDH) in association with a time-dependent increase of IL-1 $\beta$ and TNF (Ilves et al. 2018). 
Fibroblasts have been commonly used to evaluate the CNF cytotoxicity due to its potential as a wound dressing material. In a study with cotton CNFs (length 85-225 $\mu \mathrm{m}$; width 6-18 nm), concentrations above $200 \mu \mathrm{g} / \mathrm{mL}$ decreased cell viability of bovine fibroblasts, as assessed by flow cytometry, and, at a concentration of $2000-5000 \mu \mathrm{g} / \mathrm{mL}$, there was an increase in the expression of the stress response genes HSP70.1, PRDX1 and the apoptotic-associated gene $B A X$ (Pereira et al. 2013). On the contrary, no cytotoxicity was observed in mouse fibroblasts (3T3) for CNFs extracted from Eucalyptus and Pinus radiata pulp, with and without TEMPO-mediated pre-treatment, in both a direct and an indirect contact assay. However, when modified with the crosslinking agent polyethyleneimine or the surfactant acetyl trimethylammonium bromide, these CNFs had a clear effect on cell viability (Alexandrescu et al. 2013). In addition, human dermal fibroblasts (hDF) exposed to carboxymethylated-CNFs, trimethyalmmonium-CNFs and the unmodified-CNFs, extracted from bleached sulphite softwood dissolving pulp, did not evidenced cytotoxic effects in direct and indirect contact tests, being the carboxymethylated CNFs the most biocompatible (Hua et al. 2014). Nordli et al. (2016) introduced a modification in TEMPO-mediated oxidation, producing CNFs (width $3.7 \pm 1.3 \mathrm{~nm}$ ) from never dried bleached Pinus radiata pulp fibres with negligible endotoxin levels (Nordli et al. 2016). Normal human dermal fibroblasts and human epidermal keratinocytes treated with this ultrapure CNFs either in aerogel or in solution $(50 \mu \mathrm{g} / \mathrm{mL}$ for $24 \mathrm{~h})$ showed that the aerogel induced a decrease of metabolic activity (MTT assay) of both cell lines, more evident in keratinocytes than in fibroblasts, but without evidence of membrane damage (LDH assay). The CNF solution was not cytotoxic. The decrease observed in cell metabolic activity was possibly explained by the increased mechanical stress produced by the aerogel matrix, leading to a reduction in cell proliferation without cell death. To investigate if the hydrophobicity of CNFs had an impact on its cytotoxicity, Yanamala et al. (2016) studied the viability (Alamar blue and LDH assays) of A549 cells and THP-1 cells exposed $(5-300 \mu \mathrm{g} / \mathrm{mL})$ to freezedried powders of hydrophilic (uncoated; width $56 \pm 14 \mathrm{~nm}$ ) and hydrophobic forms (lignin-coated; $48 \pm 20 \mathrm{~nm}$ ) of CNFs (Yanamala et al. 2016). There was no effect in A549 cells viability, but THP-1 cells revealed a dose-dependent cell death, higher after $72 \mathrm{~h}$ post-exposure to both CNFs, being the hydrophobic form more cytotoxic than the hydrophilic one (uncoated). It should be noted that the lignin coating decreased the average lengths of the CNF particles that were more dispersed in TEM/AFM analysis, as compared to the uncoated CNFs. The agglomeration of uncoated CNFs can reduce their contact with the cells, explaining the lower cytotoxicity of the hydrophilic CNFs. Other vegetal biomass sources of CNFs or other cellular models have been used without reportable cytotoxicity. No cytotoxicity was observed in indirect and direct tests with CNF from Curauá leaf fibres (width $6.4 \pm 4.6 \mathrm{~nm}$ ) in Vero cells, which instead showed higher adhesion to the surface and growing than the untreated culture (Souza et al. 2018). Tibolla et al. (2019) reported significant cytotoxicity in $\mathrm{CaCO}-2$ cells exposed to $\mathrm{CNCs}$ isolated from banana peel at concentrations above $2000 \mu \mathrm{g} / \mathrm{mL}$ (Tibolla et al. 2019). No acute toxicity (highest tolerated dose and total protein content) and only sub-lethal effects (RNA synthesis inhibition) was observed in a human cervix carcinoma (HeLa229) cell line exposed for $24 \mathrm{~h}$ and $72 \mathrm{~h}$ to CNFs from bleached hardwood kraft pulp (width 20-40 nm), although a significant decrease in the total protein content was observed for the highest CNF concentration (Pitkänen et al. 2014). No cytotoxicity was also detected in the tri-culture model of small intestinal epithelium used in the DeLoid et al. (2019) study after $24 \mathrm{~h}$ exposure to intestinal digesta containing CNFs at 0.75 or $1.5 \%$ w/w (DeLoid et al. 2019).

The oxidative damage caused by CNFs, either in gel or powder, was assessed by the GSH and protein sulfhydryl (SH) levels in A549 cells exposed for $24 \mathrm{~h}$ and $72 \mathrm{~h}$. All the three concentrations tested led to a dose-dependent significantly decrease in the levels of GSH and SH at both time points, with lower levels detected at $72 \mathrm{~h}$, as compared to $24 \mathrm{~h}$, indicating the induction of oxidative stress (Menas et al. 2017). On the contrary, no significant increase in intracellular ROS was observed in THP-1 cells treated with a pristine, an anionic and a cationic surface-modified CNFs (Lopes et al. 2017). As already mentioned, ROS production also was assessed in DeLoid et al. (2019) study of digested CNCs and CNFs, with no increase of ROS production upon CNF exposure (DeLoid et al. 2019). 
Concerning genotoxicity assessment, CNFs obtained from cotton and curauá were the first to be evaluated for its genotoxicity in human lymphocytes (comet assay) and 3T3 cell mouse fibroblasts (de Lima et al. 2012). Genotoxic effects were observed in cells exposed to curauá CNFs (mitotic index and DNA degradation) and to brown cotton CNFs (DNA degradation and DNA damage assessed by the comet assay). Neither the white, green or ruby cotton showed to be genotoxic. Importantly, genotoxic effects were reported by Ventura et al. (2018a) who observed an increase in the frequency of micronuclei in A549 cells co-cultured with THP-1 macrophages exposed to 1.5 and $3 \mu \mathrm{g} / \mathrm{cm}^{2}$ of CNFs obtained from bleached Eucaliptus globulus kraft pulp by TEMPO-mediated oxidation (width $25.9 \mathrm{~nm}$ ) (Ventura et al. 2018a). No DNA damage was detected in the comet assay, with and without FpG treatment, suggesting that the CNFs failed to induce DNA damage and oxidative DNA lesions. The detection of chromosomal damage in this co-culture model suggests that it can be more sensitive for detection of genotoxic effects than the conventional cell monocultures.

From the studies described, no clear conclusions can be drawn about the CNF cytotoxicity, given that conflicting results have been obtained, ranging from a complete absence of toxicity up to a moderate cytotoxic effect. Interestingly, some studies have even reported increased cell viability in the presence of CNFs in culture, suggesting that it may be suitable for use as a matrix for cell growth or tissue regeneration. Nevertheless, this effect can also raise some concern as cell hyperproliferation may be associated to a tumor promoter effect. On the other hand, more studies are needed to assess the genotoxicity of CNFs, in order to ascertain their potential carcinogenic effect.

Likewise the in vitro studies of CNC, also the CNF toxicological studies are resumed in Table 2.

CNC and CNF toxicity in in vivo studies

\section{Nanocellulose absorption}

In in vivo studies, the histological examination of target tissues following animals' exposure to nanocellulose may allow the identification of fibres' deposition patterns. For instance, in the study reported by Park et al. (2018), microscopic examination of the bronchoalveolar lavage (BAL) fluid from exposed mice revealed that CNMs remained in the lungs 14 days after pharyngeal aspiration, being completely engulfed by the phagocytes (Park et al. 2018). Likewise, in another work, the microscopic analysis of BAL cells from mice exposed through intratracheal instillation (Hadrup et al. 2019) revealed that CNFs and CNTs were taken up by alveolar macrophages, whereas asbestos seemed to penetrate through the cell membranes causing cytoplasmic extensions. After 28 days post-exposure, CNFs were visualized in the alveolar region close to terminal bronchioles of exposed mice, often phagocytosed by macrophages, or appearing as aggregates larger than macrophages. In contrast, there was no evident staining of CNFs in the liver, suggesting that their levels were too low or that they did not reach the liver after pulmonary exposure (Hadrup et al. 2019).

\section{Immunotoxicity}

Regarding CNCs, the local and systemic inflammatory potential of two forms of wood derived-CNC in a 10 wt $\%$ gel/suspension or in powder was studied by Yanamala et al. (2014) in adult female C57BL/6 mice (7-8 week old) exposed by pharyngeal aspiration to 50-200 $\mu \mathrm{g} / \mathrm{mouse}$, and compared to that of asbestos (Yanamala et al. 2014). Twenty four hours after exposure, an increase in the total number of cells was found in the BAL fluid with an accelerated recruitment of neutrophils, lymphocytes, and eosinophils, and a dose-dependent increase in polymorphonuclear neutrophils (PMN). Overall, exposure to powder CNCs was able to induce a more prominent increase in BAL cells, with the accumulation of eosinophils, while exposure to $\mathrm{CNCs}$ in suspension caused higher oxidative stress. This difference could be partially due to the differences in the $\mathrm{CNC}$ dimensions, since the range of $\mathrm{CNC}$ in suspension was $90.2 \pm 3.0 \mathrm{~nm}$ (length) and 7.2 $\pm 2.1 \mathrm{~nm}$ (width) while in powder was $207.9 \pm 49.0 \mathrm{~nm}$ (length) and $8.2 \pm 2.3 \mathrm{~nm}$ (width). The overall higher levels of PMNs and other inflammatory cells upon CNC exposure as compared to asbestos indicated that $\mathrm{CNC}$ elicited a more severe acute inflammatory response. A total of 12 cytokines, including interleukins (IL-1 $\alpha$, IL-1 $\beta$, IL-5, IL-6, IL$12 \mathrm{p} 40$ ), and TNF- $\alpha$ were significantly up-regulated in CNC-exposed mice, and the majority was also elevated in the asbestos-exposed ones. On the other hand, mice exposed to the CNC suspension displayed 
a type $1 \mathrm{~T}$ helper cell (Th1) immune response and a stronger acute inflammatory response while $\mathrm{CNC}$ powder-exposed animals showed type $2 \mathrm{~T}$ helper cell (Th2) responses, i.e., an allergic inflammation. Interestingly, the pattern of up-regulated cytokines/ chemokines was less prominent in mice exposed to asbestos. White blood cells counts were significantly increased after exposure to both forms of CNC (200 $\mu \mathrm{g} /$ mouse) what clearly indicates an acute systemic inflammation. These results show that the morphology and dimensions of CNCs may be critical factors affecting the type of innate immune inflammatory response in lungs and that the immune response is gender specific.

A posterior study from the same group was performed with C57BL/6 female and male mice (7-8 weeks) to explore gender differences in response to CNC longer exposures (Shvedova et al. 2016). Mice were exposed by pharyngeal aspiration to wood pulpderived CNC (length $158 \pm 97 \mathrm{~nm}$; width $54 \pm 17 \mathrm{~nm}) 2$ times a week for 3 weeks. After 3 months post-exposure (cumulative dose of $240 \mu \mathrm{g} /$ mouse) a significant rise in total cell numbers and macrophages was detected in the BAL, with female mice showing a higher increase in total PMN and lymphocytes as compared to male mice. Histopathological analysis and determination of proinflammatory cytokines and chemokines in BAL fluid showed that female developed a more accentuated inflammatory response to $\mathrm{CNC}$ than male mice. A similar trend was seen regarding markers of oxidative stress, in that $\mathrm{CNC}$ exposure was associated to a higher decrease in the antioxidant defense reserves in females compared to males, although both genders were affected. Summing up, accelerated oxidative stress, elevated TGF- $\beta$, and collagen deposition in the lungs of CNC exposed mice were highly expressed in female compared to male mice, highlighting gender differences in the pulmonary response to CNC exposure.

Recruitment of neutrophils, macrophages, lymphocytes and eosinophils was also observed in the lungs of female $\mathrm{C} 57 \mathrm{Bl} / 6$ mice (7-8 weeks old) exposed by pharyngeal aspiration to a CNF obtained by TEMPOmediated oxidation (length 300-1000 nm; thickness $10-25 \mathrm{~nm}$ ), indicating an acute inflammatory response (Catalán et al. 2017). A significant dosedependent increase in the mRNA expression of TNF$\alpha$, IL-1 $\beta$, IL- 6 , and RANTES was also found at the highest dose of CNF (200 $\mu \mathrm{g} /$ mouse), although their protein levels remained unaffected. Park et al. (2018) assessed the inflammatory responses in the lungs of BALB/c mice (female, 7-8-week-old) 14 days after exposure by oropharyngeal aspiration of nanosized materials with fibrous morphology that included CNF and CNC (40 and $80 \mu \mathrm{g}$ per mouse) (Park et al. 2018). Total cell number, mononuclear phagocytes and PMN were increased in BAL of the animals exposed to the highest doses of both nanocelluloses. The amount of total protein and LDH activity was not increased. At 14 days after exposure, CNC induced low toxicity and a gradual time-dependent alleviation of inflammation, and CNF a differentiation of T-cells toward a Th1phenotype that was more obvious in high-dose exposure group. The clear demarcation in the clustering analysis of cytokines induced by $\mathrm{CNC}$ and $\mathrm{CNF}$, and the clustering of CNF with CNT, suggested a differential pattern of cytokine pathways between fibrous and crystalline cellulose with the later having more similarity with those induced by fibrous carbonaceous nanomaterials.

As mentioned, besides morphology (high aspect ratio), fibre functionalization is a relevant aspect for the nanomaterial toxicity. Ilves et al. (2018) studied four different CNFs obtained from wood-based pulp and compared their effects with bulk-sized cellulose fibrils and CNT in female C57BL/6 mice exposed to 10 or $40 \mu \mathrm{g} / \mathrm{mouse}$ of the tested material (Ilves et al. 2018). After $24 \mathrm{~h}$ exposure, none of the CNF affected the macrophage counts, but all induced a significant influx of neutrophils into the BAL. Moreover, the bulk-size cellulose and the two non-functionalized $\mathrm{CNF}$, all with slightly negative zeta potential, induced the recruitment of eosinophils to BAL, with the last two also elevating the lymphocytes. Supporting these finding, neutrophils and some eosinophils were detected in lung tissue after treatment with these CNFs. Compared to CNT, all CNF were less potent in causing inflammation, but were similar or exceeded those caused by the bulk material. Moreover, when compared with the Catalán et al (2017) study that used the same animal model and the same CNF doses, the CNFs used by Ilves et a. (2018) had a higher inflammatory potency (Catalán et al. 2017; Ilves et al. 2018). Regarding cytokine expression, all materials up-regulated the expression of IL-6 in lung tissue, associated to neutrophil trafficking in acute inflammation. The bulk-sized cellulose and the nonfunctionalized CNF elevated the expression of IL-1 $\beta$, 
but not the carboxymethylated $\mathrm{CNF}$ or the carboxylic acid groups-CNF. The two non-functionalized CNF also up-regulated TNF- $\alpha$ and IL-13. No marked immune reaction was observed after 28 days. When evaluating the presence of agglomerates in lung tissue, there was no significant reduction of agglomerates of cellulose materials in the lungs by day 28 , as compared to $24 \mathrm{~h}$, and the two non-functionalized CNF were the ones with a higher amount. All cellulose materials reached the alveolar space. Hadrup et al. (2019) explored whether the pulmonary and systemic toxicity of CNF could be reduced by its carboxylation (Hadrup et al. 2019). Female C57BL/6 mice (7-8 weeks old) were exposed by intratracheal instillation to 6 or $18 \mu \mathrm{g}$ CNF obtained from natural wood-based pulp. Since $\mathrm{CNF}$ in dispersion is viscous, exposure by intratracheal instillation may result in a more efficient alveolar dosing than aspiration. Comparing the CNF produced with an enzymatic pre-treatment with the one with a carboxylated $70 \%$ crystallinity structure, they observed that $\mathrm{CNF}$ with carboxylated $\mathrm{OH}$ groups induced less inflammation in terms of BAL neutrophils and less systemic acute phase response in terms of the plasma level of SAA3 as compared with the enzymatic CNF. This observation suggests involvement of $\mathrm{OH}$ groups in the inflammatory and acute phase responses, and that this may be a strategy to lower the pulmonary toxicity of CNF. In addition, the enzymatic CNF appeared to be more potent than CNT in inducing systemic acute phase response, since it increased SAA3 levels in plasma at much lower doses.

\section{Cytotoxicity and oxidative damage}

Since cellulose at the micro-scale and its derivatives have been widely used as a thicker and filler in foods and drugs, a recent semi-chronic study was performed to evaluate the toxicological effects of ingested CNF (DeLoid et al. 2019). Male Wistar Han rats (12 weeks old) were exposed to a CNF (mean width $64 \mathrm{~nm}$ ) produced by mechanical grinding of dried sheets of softwood bleached kraft fibre, alone or in a food matrix. In addition, a triculture was used parallel, as already discussed in the in vitro section. No significant differences were found in blood counts, haematological measurements (haemoglobin concentration, haematocrit, mean corpuscular volume, mean corpuscular haemoglobin, mean corpuscular haemoglobin concentration, platelet count or mean platelet volume), serum markers (total cholesterol, HDL, LDL, free fatty acid), markers of hepatic function (AST, ALT, ALP, total protein, albumin), markers of renal function (total bilirubin, creatinine) or electrolytes (sodium, potassium, chloride). Histopathology did not reveal significant findings also, suggesting that CNF has little acute toxicity and probably can be considered as nontoxic when ingested in small quantities.

Concerning CNC. an increase of up to 1.63-fold and 1.57-fold in LDH activity, a marker of cell membrane damage, was found in the lungs of adult female C57BL/6 mice after pharyngeal aspiration of a $10 \mathrm{wt}$ $\% \mathrm{CNC}$ gel/suspension and in powder, respectively (Yanamala et al. 2014). Oxidative damage was evaluated by the presence of 4-hydroxynonenal (4$\mathrm{HNE}$ ) and protein carbonyl formation. A dose-dependent increase in the accumulation of protein carbonyls was detected upon exposure to $\mathrm{CNC}$, with a higher effect in the suspension, as compared to the powder CNC. Both CNC formulations caused an increase in 4-HNE levels, albeit at higher concentrations (100 and $200 \mu \mathrm{g}$ per mouse). Overall, the magnitude of oxidative damage was more pronounced in the lungs of mice treated with $\mathrm{CNC}$ than in those treated with asbestos (Yanamala et al. 2014). The same mice exposed by pharyngeal aspiration to a wood pulp-derived CNC, two times a week for three weeks, also revealed pulmonary tissue damage after 3 months post-exposure, as assessed by LDH and total protein activity in BAL (cumulative dose of $240 \mu \mathrm{g} /$ mouse) (Shvedova et al. 2016).

\section{Genotoxicity and gene expression studies}

Presently, there are limited in vivo studies documenting the genotoxic effects of CNCs. To our knowledge, the first study was conducted in female C57B1/6 mice exposed to a TEMPO-mediated oxidation CNF (length 300-1000 nm; thickness 10-25 nm), administrated by a single pharyngeal aspiration of $10,40,80$ and $200 \mu \mathrm{g} /$ mouse (Catalán et al. 2017). After 24 h, DNA damage was assessed by the comet assay in the BAL and lung cells, and chromosome damage by the bone marrow micronucleus assay. A significant increase in the percentage of DNA in tail was observed at the two lower doses of CNF in lung cells, whereas no increase was seen in BAL cells. No effects were detected in the bone marrow micronucleus assay. Increased DNA 
damage was also observed with an enzymatic noncarboxilated CNF in lung tissue, and with a carboxylated CNF in BAL fluid of exposed mice, although a dose-response relationship was not observed (Hadrup et al. 2019).

Gene expression studies using novel high-throughput technologies have been a promising tool to unravel the molecular mechanisms of toxicity, and some "omics" studies have been already applied to investigate other nanofibres, such as CNT (Ventura et al. 2018a). Regarding CNMs, Shvedova et al. (2016) assessed global pulmonary gene expression changes in the lung tissue of mice 3 months post exposure to CNC using a high-throughput mRNA microarray (Shvedova et al. 2016). A total of 845 and 794 of the 22,486 probes were significantly differentially expressed in male and female mice, respectively, with 68 common differentially expressed genes (DEG) in both genders. In males, there was enrichment of intracellular/cytoplasmic genes with roles in biological processes focused on cellular development/function/growth and response to stimuli, and, in females, of genes localized in extracellular and plasma membrane regions carrying out biological functions related to cell adhesion, cellular metabolism/catabolism and inflammation. DEG involvement in carbohydrate/pattern/ polysaccharide and glycosaminoglycan binding were found to be commonly enriched in both genders. In males the DEG were involved in circadian rhythm signaling and in pathways related to cancer and inflammatory response while in females, DEG were mostly involved in inflammatory and immune response signalling. Moreover, the transcription regulator analysis highlighted significant enrichment of antioxidant mechanisms triggered in response to oxidative stress in males upon exposure to $\mathrm{CNC}$, but not in females.

\section{Reprotoxicity}

Spermatogenesis is a process that can be perturbed by many chemical and physical external environmental factors, and some studies have already associated exposure to nanomaterials with decreased sperm motility and abnormal sperm morphology in male rodents (Gromadzka-Ostrowska et al. 2012; Guo et al. 2009; Yoshida et al. 2009). Regarding nanocellulose, only one study was found about the effects of pulmonary exposure to $\mathrm{CNC}$ in the reproductive system of male mice (Farcas et al. 2016). Adult male C57BL/6 mice (7-8 weeks) were administered with $40 \mu \mathrm{g} / \mathrm{mouse} /$ day of a wood-pulp-derived CNC $(158 \pm 97 \mathrm{~nm}$ length, $54 \pm 17 \mathrm{~nm}$ width and $149.8 \pm 2.6 \mathrm{~nm}$ hydrodynamic width) by pharyngeal aspiration, and three months after the last administration the outcomes on their reproductive system were evaluated. CNC exposure produced a $40 \%$ decline in spermatozoa counts and $50 \%$ decrease in motile sperm cells. Morphological evaluation of sperm smear indicated a significantly increase in thin and elongated head (2.67-fold), club-shaped head (1.5-fold), looping midpiece (1.57-fold), and bent mid-piece (2.37-fold). The DNA fragmentation index was significantly elevated. These changes may be attributed to peroxidative modification of lipids of sperm plasma membrane and correlated with enhanced MPO activity and increased accumulation of several cytokines and chemokines In addition, IL-1 $\beta$, IL-2, IL-12p40, KC, MCP-1, and TNF- $\alpha$ were higher in serum of exposed animals, suggesting systemic effects of pulmonary exposure to CNC. Testicular oxidative damage, particularly in the epididymis, was also found. Histological analysis of testes sections from the CNC-exposed animals displayed mild to moderate interstitial edema and frequent dystrophic seminiferous tubules with arrested spermatogenesis and degenerating spermatocytes. Testosterone levels were elevated in testes and serum of exposed mice, and luteinizing hormone levels in serum were significantly reduced. This study clearly associated $\mathrm{CNC}$ to reprotoxic effects in mice.

All in vivo toxicological studies of $\mathrm{CNC}$ and $\mathrm{CNF}$ are shown in Table 3.

\section{Conclusions}

CNMs are promising nanomaterials with a wide range of possible applications in industry and biomedicine. However, from this literature review, it is well brought to light that nanocellulose with different physicochemical characteristics elicit different toxicological effects and further clarification of its main adverse features is lacking, in order to contribute for a saferby-design approach. CNMs in gel or powder trigger diverse immunological responses, which are possibly associated to their tendency to agglomerate when dispersed in body fluids (in vivo) or culture medium (in vitro). Nanocellulose agglomeration will affect its 
bioavailability, its cellular uptake and the interaction with the subcellular components. Thus, different functionalization affecting their hydrophobicity, surface charge and surface chemistry may either facilitate or difficult the nanocellulose uptake and the interaction of its functional groups with the cell membrane, affecting the downstream biological responses. Overall, nanocellulose uptake into cells is generally low, with no induction of oxidative stress and no significant cytotoxic and genotoxic effects. However, macrophages that, due to their phagocytic function internalize rod-like $\mathrm{CNC}$, trigger a moderate to severe inflammatory reaction, which depend on the $\mathrm{CNC}$ functionalization mainly. In contrast, long CNFs generally are not phagocytized and do not cause an inflammatory response. However, CNF revealed significant genotoxicity, both in vivo (DNA damage) and in vitro (chromosomal damage). These outcomes are apparently milder than the ones observed for other nanofibres, such as some CNT, for which several rodent studies demonstrated severe adverse effects, including pulmonary inflammation, interstitial fibrosis, granuloma, bronchioloalveolar hyperplasia and even cancer. Accordingly, in vitro studies evidenced more consistent cytotoxic, genotoxic and immunotoxic effects for CNT, than for the CNMs addressed in this work. These noticed disparities may be related to differences in the physicochemical properties of these two classes of nanofibres, e.g., rigidity or surface properties, although both display high aspect ratio and biopersistency On the other hand, gene expression studies and other new "omics" approaches are still in its infancy in the field of nanocellulose toxicology and need to be further developed to give insights into the cells response against CNMs and consequent effects. Considering the CNMs physicochemical characteristics (size and surface charge, particularly) it is essential to design safer CNMs for endless applications, and to prevent adverse health effects resulting from oral, dermal or respiratory human exposure, in order to accomplish safe and sustainable innovative applications.

Acknowledgments The authors acknowledge CYTED network NANOCELIA (Transferencia Tecnológica sobre aplicaciones de nanocelulosa en iberoamérica). The work was funded by FCT/MCTES, Project ToxApp4NanoCELFI (PTDC/ SAU-PUB/32587/2017) through national funds (PIDDAC), and co-funded by ToxOmics - Center for Toxicogenomics and
Human Health (UID/BIM/00009/2013). Sara Teixeira is acknowledged for the binucleated cells photo.

\section{References}

Aaen R, Simon S, Wernersson Brodin F, Syverud K (2019) The potential of TEMPO-oxidized cellulose nanofibrils as rheology modifiers in food systems. Cellulose 26:5483-5496. https://doi.org/10.1007/s10570-01902448-3

Abdul Khalil HPS, Bhat AH, Ireana Yusra AF (2012) Green composites from sustainable cellulose nanofibrils: a review. Carbohydr Polym 87:963-979. https://doi.org/10. 1016/j.carbpol.2011.08.078

Abdul Khalil HPS, Davoudpour Y, Islam MN, Mustapha A, Sudesh K, Dungani R, Jawaid M (2014) Production and modification of nanofibrillated cellulose using various mechanical processes: a review. Carbohydr Polym 99:649-665. https://doi.org/10.1016/j.carbpol.2013.08. 069

Abitbol T, Rivkin A, Cao Y, Nevo Y, Abraham E, Ben-Shalom T, Lapidot S, Shoseyov O (2016) Nanocellulose, a tiny fiber with huge applications. Curr Opin Biotechnol 39:76-88. https://doi.org/10.1016/j.copbio.2016.01.002

Alexandrescu L, Syverud K, Gatti A, Chinga-Carrasco G (2013) Cytotoxicity tests of cellulose nanofibril-based structures. Cellulose 20:1765-1775. https://doi.org/10.1007/s10570013-9948-9

Alzate-Arbeláez AF, Dorta E, López-Alarcón C, Cortés FB, Rojano BA (2019) Immobilization of Andean berry (Vaccinium meridionale) polyphenols on nanocellulose isolated from banana residues: a natural food additive with antioxidant properties. Food Chem 294:503-517. https:// doi.org/10.1016/j.foodchem.2019.05.085

Azizi Samir MAS, Alloin F, Dufresne A (2005) Review of recent research into cellulosic whiskers, their properties and their application in nanocomposite field. Biomacromol 6:612-626

Bai W, Holbery J, Li K (2009) A technique for production of nanocrystalline cellulose with a narrow size distribution. Cellulose 16:455-465

Balea A, Fuente E, Blanco A, Negro C (2019) Nanocelluloses: natural-based materials for fiber-reinforced cement composites: a critical review. Polymers (Basel) 11:518. https:// doi.org/10.3390/polym11030518

Barhoum A, Samyn P, Öhlund T, Dufresne A (2017) Review of recent research on flexible multifunctional nanopapers. Nanoscale 9:15181-15205. https://doi.org/10.1039/ C7NR04656A

Beck-Candanedo S, Roman M, Gray DG (2005) Effect of reaction conditions on the properties and behavior of wood cellulose nanocrystal suspensions. Biomacromol 6:1048-1054. https://doi.org/10.1021/bm049300p

Bras J, Saini S (2017) Nanocellulose in functional packaging. In: Jawaid M, Boufi S, H.P.S AK (eds) Cellulose-Reinforced Nanofibre Composites. Woodhead Publishing, pp 175-213. https://doi.org/10.1016/B978-0-08-100957-4. 00008-5 
Bras J, Viet D, Bruzzese C, Dufresne A (2011) Correlation between stiffness of sheets prepared from cellulose whiskers and nanoparticles dimensions. Carbohydr Polym 84:211-215. https://doi.org/10.1016/j.carbpol.2010.11. 022

Brinchi L, Cotana F, Fortunati E, Kenny JM (2013) Production of nanocrystalline cellulose from lignocellulosic biomass: technology and applications. Carbohydr Polym 94:154-169. https://doi.org/10.1016/j.carbpol.2013.01. 033

Cacciotti I, Fortunati E, Puglia D, Kenny JM, Nanni F (2014) Effect of silver nanoparticles and cellulose nanocrystals on electrospun poly(lactic) acid mats: Morphology, thermal properties and mechanical behavior. Carbohydr Polym 103:22-31. https://doi.org/10.1016/j.carbpol.2013.11.052

Catalán J, Ilves M, Jarventaus H, Hannukainen KS, Kontturi E, Vanhala E, Alenius H, Savolainen KM, Norppa H (2015) Genotoxic and immunotoxic effects of cellulose nanocrystals in vitro. Environ Mol Mutagen 56:171-182. https://doi.org/10.1002/em.21913

Catalán J, Rydman E, Aimonen K, Hannukainen KS, Suhonen S, Vanhala E, Moreno C, Meyer V, Perez DD, Sneck A, Forsstrom U, Hojgaard C, Willemoes M, Winter JR, Vogel U, Wolff H, Alenius H, Savolainen KM, Norppa H (2017) Genotoxic and inflammatory effects of nanofibrillated cellulose in murine lungs. Mutagenesis 32:23-31. https:// doi.org/10.1093/mutage/gew035

Ching YC, Gunathilake TMSU, Chuah CH, Ching KY, Singh R, Liou N-S (2019) Curcumin/Tween 20-incorporated cellulose nanoparticles with enhanced curcumin solubility for nano-drug delivery: characterization and in vitro evaluation. Cellulose 26:5467-5481. https://doi.org/10.1007/ s10570-019-02445-6

Das K, Ray D, Bandyopadhyay NR, Ghosh T, Mohanty AK, Misra M (2009) A study of the mechanical, thermal and morphological properties of microcrystalline cellulose particles prepared from cotton slivers using different acid concentrations. Cellulose 16:783-793. https://doi.org/10. 1007/s10570-009-9280-6

de Lima R, Oliveira Feitosa L, Rodrigues Maruyama C, Abreu Barga M, Yamawaki PC, Vieira IJ, Teixeira EM, Correa AC, Caparelli Mattoso LH, Fernandes Fraceto L (2012) Evaluation of the genotoxicity of cellulose nanofibers. Int $\mathbf{J}$ Nanomed 7:3555-3565. https://doi.org/10.2147/ijn. s30596

de Mesquita JP, Donnici CL, Pereira FV (2010) Biobased nanocomposites from layer-by-layer assembly of cellulose nanowhiskers with Chitosan. Biomacromol 11:473-480. https://doi.org/10.1021/bm9011985

DeLoid GM, Cao X, Molina RM, Silva DI, Bhattacharya K, Ng KW, Loo SCJ, Brain JD, Demokritou P (2019) Toxicological effects of ingested nanocellulose in in vitro intestinal epithelium and in vivo rat models. Environ Sci Nano 6:2105-2115. https://doi.org/10.1039/C9EN00184K

Despres HW, Sabra A, Anderson P, Hemraz UD, Boluk Y, Sunasee R, Ckless K (2019) Mechanisms of the immune response cause by cationic and anionic surface functionalized cellulose nanocrystals using cell-based assays. Toxicol In Vitro 55:124-133. https://doi.org/10.1016/j.tiv. 2018.12.009
Dong S, Hirani AA, Colacino KR, Lee YW, Roman M (2012) Cytotoxicity and cellular uptake of cellulose nanocrystals. Nano Life 2:1241006

Dufresne A (2012a) CHAPTER 1 Nanocellulose: Potential Reinforcement in Composites. In: Natural polymers: nanocomposites, vol 2. The Royal Society of Chemistry, pp 1-32. https://doi.org/10.1039/9781849735315-00001

Dufresne A (2012) Nanocellulose: from nature to high performance tailored materials. De Gruyter Nanocellulose. https://doi.org/10.1515/9783110254600

Dufresne A (2013) Nanocellulose: a new ageless bionanomaterial. Mater Today 16:220-227. https://doi.org/10.1016/j. mattod.2013.06.004

Dufresne A (2019) Nanocellulose processing properties and potential applications. Curr For Rep 5:76-89. https://doi. org/10.1007/s40725-019-00088-1

Eastlake A, Rudie A, Geraci C (2014) Nanocellulose-evaluation of the full spectrum of workplace health and safety Technical Proceedings of the 2014 NSTI Nanotechnology Conference and Expo, NSTI-Nanotech 2014 3:105-108

Engström A-C, Ek M, Henriksson G (2006) Improved accessibility and reactivity of dissolving pulp for the viscose process: pretreatment with monocomponent endoglucanase. Biomacromol 7:2027-2031

Erdem SJ, Alswady-Hoff M, Ervik TK, Skare Ø, Ellingsen DG, Zienolddiny S (2019) Cellulose nanocrystals modulate alveolar macrophage phenotype and phagocytic function. Biomaterials 203:31-42. https://doi.org/10.1016/j. biomaterials.2019.02.025

European Commission (2009) Preparing for our future: Developing a comm on strategy for key enabling technologies in the EU. COM(2009) 512 final

European Parliament (2010) European Parliament resolution of 24 April 2009 on regulatory aspects of nanomaterials (2008/2208(INI). European Parliament

Eyley S, Thielemans W (2014) Surface modification of cellulose nanocrystals. Nanoscale 6:7764-7779. https://doi.org/10. 1039/C4NR01756K

Fang Z, Zhu H, Preston C, Hu L (2014) Development, application and commercialization of transparent paper. Transl Mater Res 1:015004

Fengel D, Wegener G (1983) Wood: chemistry, ultrastructure, reactions. Walter de Gruyter

Foster EJ, Moon RJ, Agarwal UP, Bortner MJ, Bras J, Camarero-Espinosa S, Chan KJ, Clift MJD, Cranston ED, Eichhorn SJ, Fox DM, Hamad WY, Heux L, Jean B, Korey M, Nieh W, Ong KJ, Reid MS, Renneckar S, Roberts R, Shatkin JA, Simonsen J, Stinson-Bagby K, Wanasekara N, Youngblood J (2018) Current characterization methods for cellulose nanomaterials. Chem Soc Rev 47:2609-2679. https://doi.org/10.1039/C6CS00895J

Garcia de Rodriguez NL, Thielemans W, Dufresne A (2006) Sisal cellulose whiskers reinforced polyvinyl acetate nanocomposites. Cellulose 13:261-270. https://doi.org/10. 1007/s10570-005-9039-7

Gatenholm P, Klemm D (2010) Bacterial nanocellulose as a renewable material for biomedical applications. MRS Bull 35:208-213

Gotta J, Shalom TB, Aslanoglou S, Cifuentes-Rius A, Voelcker NH, Elnathan R, Shoseyov O, Richter S (2018) Stable white light-emitting biocomposite films. Adv Funct 
Mater 28:1706967. https://doi.org/10.1002/adfm. 201706967

Grishkewich N, Mohammed N, Tang J, Tam KC (2017) Recent advances in the application of cellulose nanocrystals. Curr Opin Colloid Interface Sci 29:32-45. https://doi.org/10. 1016/j.cocis.2017.01.005

Gromadzka-Ostrowska J, Gromadzka-Ostrowska J, Dziendzikowska K, Lankoff A, Dobrzynska M, Instanes C, Brunborg G, Gajowik A, Radzikowska J, Wojewodzka M, Kruszewski M (2012) Silver nanoparticles effects on epididymal sperm in rats. Toxicol Lett 214:251-258. https:// doi.org/10.1016/j.toxlet.2012.08.028

Guo L, Liu X-H, Qin D, Gao L, Zhang H, Liu J-Y, Cui Y (2009) Effects of nanosized titanium dioxide on the reproductive system of male mice. Natl J Androl 15:517-522

Habibi Y (2014) Key advances in the chemical modification of nanocelluloses. Chem Soc Rev 43:1519-1542. https://doi. org/10.1039/C3CS60204D

Habibi Y, Lucia LA, Rojas OJ (2010) Cellulose nanocrystals: chemistry, self-assembly, and applications. Chem Rev 110:3479-3500. https://doi.org/10.1021/cr900339w

Hadrup N, Knudsen KB, Berthing T, Wolff H, Bengtson S, Kofoed C, Espersen R, Højgaard C, Winther JR, Willemoës M, Wedin I, Nuopponen M, Alenius H, Norppa H, Wallin H, Vogel U (2019) Pulmonary effects of nanofibrillated celluloses in mice suggest that carboxylation lowers the inflammatory and acute phase responses. Environ Toxicol Pharmacol 66:116-125. https://doi.org/10.1016/j. etap.2019.01.003

Han J, Lei T, Wu Q (2014) High-water-content mouldable polyvinyl alcohol-borax hydrogels reinforced by welldispersed cellulose nanoparticles: dynamic rheological properties and hydrogel formation mechanism. Carbohydr Polym 102:306-316. https://doi.org/10.1016/j.carbpol. 2013.11.045

Hanif Z, Ahmed FR, Shin SW, Kim YK, Um SH (2014) Sizeand dose-dependent toxicity of cellulose nanocrystals (CNC) on human fibroblasts and colon adenocarcinoma. Colloids Surf B 119:162-165. https://doi.org/10.1016/j. colsurfb.2014.04.018

Hayashi N, Kondo T, Ishihara M (2005) Enzymatically produced nano-ordered short elements containing cellulose I $\beta$ crystalline domains. Carbohyd Polym 61:191-197. https:// doi.org/10.1016/j.carbpol.2005.04.018

Henriksson M, Henriksson G, Berglund LA, Lindström T (2007) An environmentally friendly method for enzyme-assisted preparation of microfibrillated cellulose (MFC) nanofibers. Eur Polym J 43:3434-3441. https://doi.org/10.1016/j. eurpolymj.2007.05.038

Hoeger IC Microscopic Analysis of Cellulose Nanofibril (CNF)and Cellulose Nanocrystal (CNC)-Based Nanocomposites. In: Handbook of Nanocellulose and Cellulose Nanocomposites. pp 365-392. https://doi.org/10.1002/ 9783527689972.ch11

Hoeng F, Denneulin A, Bras J (2016) Use of nanocellulose in printed electronics: a review. Nanoscale 8:13131-13154. https://doi.org/10.1039/c6nr03054h

Hosseinidoust Z, Alam MN, Sim G, Tufenkji N, van de Ven TG (2015) Cellulose nanocrystals with tunable surface charge for nanomedicine. Nanoscale 7:16647-16657. https://doi. org/10.1039/c5nr02506k
Hua K, Carlsson DO, Ålander E, Lindström T, Strømme M, Mihranyan A, Ferraz N (2014) Translational study between structure and biological response of nanocellulose from wood and green algae. RSC Adv 4:2892-2903. https://doi. org/10.1039/C3RA45553J

Hubbe MA, Rojas OJ, Lucia LA (2015) Green modification of surface characteristics of cellulosic materials at the molecular or nano scale: a review. BioResources 10:6095-6206

Ilves M, Vilske S, Aimonen K, Lindberg HK, Pesonen S, Wedin I, Nuopponen M, Vanhala E, Hojgaard C, Winter JR, Willemoes M, Vogel U, Wolff H, Norppa H, Savolainen K, Alenius H (2018) Nanofibrillated cellulose causes acute pulmonary inflammation that subsides within a month. Nanotoxicology 12:729-746. https://doi.org/10.1080/ 17435390.2018.1472312

Islam MN, Rahman F (2019) Production and modification of nanofibrillated cellulose composites and potential applications. In: Koronis G, Silva A (eds) Green composites for automotive applications. Woodhead Publishing, Swaston, pp 115-141

Islam MS, Chen L, Sisler J, Tam KC (2018) Cellulose nanocrystal (CNC)-inorganic hybrid systems: synthesis, properties and applications. J Mater Chem B 6:864-883. https://doi.org/10.1039/C7TB03016A

ISO (2017) Nanotechnologies-Standard terms and their definition for cellulose nanomaterial. ISO, Geneva

Isobe N, Sekine M, Kimura S, Wada M, Kuga S (2011) Anomalous reinforcing effects in cellulose gel-based polymeric nanocomposites. Cellulose 18:327-333. https://doi.org/10. 1007/s10570-010-9487-6

Isogai A (2013) Wood nanocelluloses: fundamentals and applications as new bio-based nanomaterials. J Wood Sci 59:449-459. https://doi.org/10.1007/s10086-013-1365-z

Isogai A, Bergström L (2018) Preparation of cellulose nanofibers using green and sustainable chemistry. Current Opinion in Green and Sustainable Chemistry 12:15-21

Isogai A, Saito T, Fukuzumi H (2011) TEMPO-oxidized cellulose nanofibers. Nanoscale 3:71-85. https://doi.org/10. 1039/c0nr00583e

Isogai A, Zhou Y (2019) Diverse nanocelluloses prepared from TEMPO-oxidized wood cellulose fibers: nanonetworks, nanofibers, and nanocrystals. Curr Opin Solid State Mater Sci 23:101-106. https://doi.org/10.1016/j.cossms.2019.01. 001

Johansson L-S, Tammelin T, Campbell JM, Setälä H, Österberg M (2011) Experimental evidence on medium driven cellulose surface adaptation demonstrated using nanofibrillated cellulose. Soft Matter 7:10917-10924

Kane AB, Hurt RH, Gao H (2018) The asbestos-carbon nanotube analogy: an update. Toxicol Appl Pharmacol 361:68-80. https://doi.org/10.1016/j.taap.2018.06.027

Kang W, Yan C, Foo CY, Lee PS (2015) Foldable electrochromics enabled by nanopaper transfer method. Adv Func Mater 25:4203-4210. https://doi.org/10.1002/adfm. 201500527

Kangas H, Lahtinen P, Sneck A, Saariaho A-M, Laitinen O, Hellen E (2014) Characterization of fibrillated celluloses. A short review and evaluation of characteristics with a combination of methods. Nordic Pulp Pap Res J 29:129-143 
Kargarzadeh H, Mariano M, Gopakumar D, Ahmad I, Thomas S, Dufresne A, Huang J, Lin N (2018) Advances in cellulose nanomaterials. Cellulose 25:2151-2189. https://doi. org/10.1007/s10570-018-1723-5

Kargarzadeh H, Mariano M, Huang J, Lin N, Ahmad I, Dufresne A, Thomas S (2017) Recent developments on nanocellulose reinforced polymer nanocomposites: a review. Polymer 132:368-393. https://doi.org/10.1016/j.polymer.2017. 09.043

Kim J-H, Lee D, Lee Y-H, Chen W, Lee S-Y (2019) Nanocellulose for energy storage systems: beyond the limits of synthetic materials. Adv Mater 31:1804826. https://doi. org/10.1002/adma.201804826

Klemm D, Kramer F, Moritz S, Lindström T, Ankerfors M, Gray D, Dorris A (2011) Nanocelluloses: a new family of naturebased materials. Angew Chem Int Ed 50:5438-5466. https://doi.org/10.1002/anie.201001273

Lasseuguette E, Roux D, Nishiyama Y (2008) Rheological properties of microfibrillar suspension of TEMPO-oxidized pulp. Cellulose 15:425-433. https://doi.org/10.1007/ s10570-007-9184-2

Lavoine N, Desloges I, Dufresne A, Bras J (2012) Microfibrillated cellulose-its barrier properties and applications in cellulosic materials: a review. Carbohydr Polymers 90:735-764. https://doi.org/10.1016/j.carbpol.2012.05. 026

Li J, Wang Y, Zhang L, Xu Z, Dai H, Wu W (2019) Nanocellulose/gelatin composite cryogels for controlled drug release. ACS Sustain Chem Eng 7:6381-6389. https://doi. org/10.1021/acssuschemeng.9b00161

Lin N, Dufresne A (2014) Nanocellulose in biomedicine: current status and future prospect. Eur Polymer J 59:302-325. https://doi.org/10.1016/j.eurpolymj.2014.07.025

Lopes VR, Sanchez-Martinez C, Strømme M, Ferraz N (2017) In vitro biological responses to nanofibrillated cellulose by human dermal, lung and immune cells: surface chemistry aspect. Part Fibre Toxicol 14:1-1. https://doi.org/10.1186/ s12989-016-0182-0

Louro H, Saruga A, Santos J, Pinhao M, Silva MJ (2019) Biological impact of metal nanomaterials in relation to their physicochemical characteristics. Toxicol In Vitro 56:172-183. https://doi.org/10.1016/j.tiv.2019.01.018

Lu P, Hsieh Y-L (2010) Preparation and properties of cellulose nanocrystals: rods, spheres, and network. Carbohydr Polym 82:329-336. https://doi.org/10.1016/j.carbpol. 2010.04.073

Lundahl MJ, Cunha AG, Rojo E, Papageorgiou AC, Rautkari L, Arboleda JC, Rojas OJ (2016) Strength and water interactions of cellulose I filaments wet-spun from cellulose nanofibril hydrogels. Sci Rep 6:30695. https://doi.org/10. 1038/srep30695

Luo H, Cha R, Li J, Hao W, Zhang Y, Zhou F (2019) Advances in tissue engineering of nanocellulose-based scaffolds: a review. Carbohydr Polym 224:115144. https://doi.org/10. 1016/j.carbpol.2019.115144

Lv D, Xu M, Liu X, Zhan Z, Li Z, Yao H (2010) Effect of cellulose, lignin, alkali and alkaline earth metallic species on biomass pyrolysis and gasification. Fuel Process Technol 91:903-909. https://doi.org/10.1016/j.fuproc.2009.09. 014
Male KB, Leung AC, Montes J, Kamen A, Luong JH (2012) Probing inhibitory effects of nanocrystalline cellulose: inhibition versus surface charge. Nanoscale 4:1373-1379. https://doi.org/10.1039/c2nr11886f

Mariano M, El Kissi N, Dufresne A (2014) Cellulose nanocrystals and related nanocomposites: review of some properties and challenges. J Polym Sci Part B 52:791-806. https://doi.org/10.1002/polb.23490

Martinez KF, Eastlake A, Rudie A, Geraci C (2013) Occupational exposure characterization during the manufacture of cellulose nanomaterials. In: Production and applications of cellulose nanomaterials. TAPPI Press, pp 61-64

Medzhitov R (2010) Inflammation 2010: new adventures of an old flame. Cell 140:771-776. https://doi.org/10.1016/j.cell. 2010.03.006

Menas AL, Yanamala N, Farcas MT, Russo M, Friend S, Fournier PM, Star A, Iavicoli I, Shurin GV, Vogel UB, Fadeel B, Beezhold D, Kisin ER, Shvedova AA (2017) Fibrillar vs crystalline nanocellulose pulmonary epithelial cell responses: cytotoxicity or inflammation? Chemosphere 171:671-680. https://doi.org/10.1016/j. chemosphere.2016.12.105

Meschini S, Pellegrini E, Maestri CA, Condello M, Bettotti P, Condello G, Scarpa M (2019) In vitro toxicity assessment of hydrogel patches obtained by cation-induced crosslinking of rod-like cellulose nanocrystals. J Biomed Mater Res Part B. https://doi.org/10.1002/jbm.b.34423

Mondal S (2017) Preparation, properties and applications of nanocellulosic materials. Carbohydr Polym 163:301-316. https://doi.org/10.1016/j.carbpol.2016.12.050

Moniruzzaman M, Ono T (2013) Separation and characterization of cellulose fibers from cypress wood treated with ionic liquid prior to laccase treatment. Biores Technol 127:132-137. https://doi.org/10.1016/j.biortech.2012.09. 113

Moon RJ, Martini A, Nairn J, Simonsen J, Youngblood J (2011) Cellulose nanomaterials review: structure, properties and nanocomposites. Chem Soc Rev 40:3941-3994. https:// doi.org/10.1039/C0CS00108B

Moon RJ, Pöohler T, Tammelin T (2013) Microscopic Characterization of Nanofibers and Nanocrystals. In: Handbook of Green Materials, vol 5. Materials and Energy, vol Volume 5. WORLD SCIENTIFIC, pp 159-180

Nathan C, Ding A (2010) Nonresolving inflammation. Cell 140:871-882. https://doi.org/10.1016/j.cell.2010.02.029

Nechyporchuk O, Belgacem MN, Bras J (2016) Production of cellulose nanofibrils: a review of recent advances. Ind Crops Prod 93:2-25

Ni H, Zeng S, Wu J, Cheng X, Luo T, Wang W, Zeng W, Chen Y (2012) Cellulose nanowhiskers: preparation, characterization and cytotoxicity evaluation. Biomed Mater Eng 22:121-127. https://doi.org/10.3233/bme-2012-0697

Nordli HR, Chinga-Carrasco G, Rokstad AM, Pukstad B (2016) Producing ultrapure wood cellulose nanofibrils and evaluating the cytotoxicity using human skin cells. Carbohydr Polym 150:65-73. https://doi.org/10.1016/j.carbpol.2016. 04.094

Ojansivu M, Rashad A, Ahlinder A, Massera J, Mishra A, Syverud K, Finne-Wistrand A, Miettinen S, Mustafa K (2019) Wood-based nanocellulose and bioactive glass modified gelatin-alginate bioinks for 3D bioprinting of 
bone cells. Biofabrication 11:035010. https://doi.org/10. 1088/1758-5090/ab0692

Or T, Saem S, Esteve A, Osorio DA, de France KJ, Vapaavuori J, Hoare T, Cerf A, Cranston ED, Moran-Mirabal JM (2019) Patterned cellulose nanocrystal aerogel films with tunable dimensions and morphologies as ultra-porous scaffolds for cell culture. ACS Appl Nano Mater 2:4169-4179. https://doi.org/10.1021/acsanm.9b00640

Pääkkö M, Ankerfors M, Kosonen H, Nykanen A, Ahola S, Österberg M, Ruokolainen J, Laine J, Larsson PT, Ikkala O (2007) Enzymatic hydrolysis combined with mechanical shearing and high-pressure homogenization for nanoscale cellulose fibrils and strong gels. Biomacromol 8:1934-1941

Pachuau L (2017) Application of nanocellulose for controlled drug delivery. Nanocellulose and Nanohydrogel Matrices: Biotechnological and Biomedical Applications:1-19

Palomaki J, Valimaki E, Sund J, Vippola M, Clausen PA, Jensen KA, Savolainen K, Matikainen S, Alenius H (2011) Long, needle-like carbon nanotubes and asbestos activate the NLRP3 inflammasome through a similar mechanism. ACS Nano 5:6861-6870. https://doi.org/10.1021/nn200595c

Park E-J, Khaliullin TO, Shurin MR, Kisin ER, Yanamala N, Fadeel B, Chang J, Shvedova AA (2018) Fibrous nanocellulose, crystalline nanocellulose, carbon nanotubes, and crocidolite asbestos elicit disparate immune responses upon pharyngeal aspiration in mice. J Immunotoxicol 15:12-23

Pereira MM, Raposo NR, Brayner R, Teixeira EM, Oliveira V, Quintao CC, Camargo LS, Mattoso LH, Brandao HM (2013) Cytotoxicity and expression of genes involved in the cellular stress response and apoptosis in mammalian fibroblast exposed to cotton cellulose nanofibers. Nanotechnology 24:075103. https://doi.org/10.1088/09574484/24/7/075103

Phanthong P, Reubroycharoen P, Hao X, Xu G, Abudula A, Guan G (2018) Nanocellulose: extraction and application. Carbon Resour Convers 1:32-43. https://doi.org/10.1016/j. crcon.2018.05.004

Pitkänen M, Kangas H, Laitinen O, Sneck A, Lahtinen P, Peresin MS, Niinimäki J (2014) Characteristics and safety of nano-sized cellulose fibrils. Cellulose 21:3871-3886. https://doi.org/10.1007/s10570-014-0397-x

Pöhler T, Lappalainen T, Tammelin T, Eronen P, Hiekkataipale P, Vehniäinen A, M. Koskinen T (2011) Influence of fibrillation method on the character of nanofibrillated cellulose (NFC)

Ramasamy J, Amanullah M (2019) Nanocellulose for oil and gas field drilling and cementing applications. J Petrol Sci Eng. https://doi.org/10.1016/j.petrol.2019.106292

ResearchAndMarkets (2018) Nanocellulose market by type, application, and region-global forecast to 2023. ID: 4659472.Dublin. Available at: https://www. researchandmarkets.com/research/jgxkwd/650_mn?w=5

Ribeiro RSA, Pohlmann BC, Calado V, Bojorge N, Pereira N Jr (2019) Production of nanocellulose by enzymatic hydrolysis: trends and challenges. Eng Life Sci 19:279-291. https://doi.org/10.1002/elsc.201800158

Rol F, Vergne B, El-Kissi N, Bras J (2019) New high solid content cellulose nanofibrils production by twin screw extrusion optimization. In: International Conference on Nanotechnology for renewable Materials-2019

Roman M, Dong S, Hirani A, Lee YW (2009) Cellulose nanocrystals for drug delivery. ACS Publications, Washington, DC

Roman M, Winter WT (2004) Effect of sulfate groups from sulfuric acid hydrolysis on the thermal degradation behavior of bacterial cellulose. Biomacromol 5:1671-1677. https://doi.org/10.1021/bm034519+

Saito T, Hirota M, Tamura N, Kimura S, Fukuzumi H, Heux L, Isogai A (2009) Individualization of nano-sized plant cellulose fibrils by direct surface carboxylation using TEMPO catalyst under neutral conditions. Biomacromol 10:1992-1996. https://doi.org/10.1021/bm900414t

Saito T, Isogai A (2004) TEMPO-mediated oxidation of native cellulose. The effect of oxidation conditions on chemical and crystal structures of the water-insoluble fractions. Biomacromol 5:1983-1989. https://doi.org/10.1021/ bm0497769

Saito T, Nishiyama Y, Putaux J-L, Vignon M, Isogai A (2006) Homogeneous suspensions of individualized microfibrils from TEMPO-catalyzed oxidation of native cellulose. Biomacromol 7:1687-1691. https://doi.org/10.1021/ bm060154s

Saito T, Uematsu T, Kimura S, Enomae T, Isogai A (2011) Selfaligned integration of native cellulose nanofibrils towards producing diverse bulk materials. Soft Matter 7:8804-8809. https://doi.org/10.1039/C1SM06050C

Salah SM (2013) Application of nano-cellulose in textile. J Textile Sci Eng 3:142

Shafiei-Sabet S, Hamad WY, Hatzikiriakos SG (2012) Rheology of nanocrystalline cellulose aqueous suspensions. Langmuir 28:17124-17133. https://doi.org/10.1021/ la303380v

Shazali NAH, Zaidi NE, Ariffin H, Abdullah LC, Ghaemi F, Abdullah JM, Takashima I, Nik Abd Rahman NMA (2019) Characterization and cellular internalization of spherical cellulose nanocrystals (CNC) into normal and cancerous fibroblasts materials (Basel, Switzerland) 12. https://doi. org/10.3390/ma12193251

Sheikhi A (2019) Emerging cellulose-based nanomaterials and nanocomposites. In: Karak $\mathrm{N}$ (ed) Nanomaterials and polymer nanocomposites. Elsevier, Amsterdam, pp 307-351

Sheikhi A, Hayashi J, Eichenbaum J, Gutin M, Kuntjoro N, Khorsandi D, Khademhosseini A (2019) Recent advances in nanoengineering cellulose for cargo delivery. J Control Release 294:53-76. https://doi.org/10.1016/j.jconrel.2018. 11.024

Shmulsky R, Jones PD (2011) Forest products and wood science: an introduction. Wiley, New York

Shoseyov O, Kam D, Ben Shalom T, Shtein Z, Vinkler S, Posen Y (2019) Nanocellulose composite biomaterials in industry and medicine. In: Cohen E, Merzendorfer H (eds) Extracellular sugar-based biopolymers matrices. Springer, Cham, pp 693-784

Shvedova AA, Kisin ER, Yanamala N, Farcas MT, Menas AL, Williams A, Fournier PM, Reynolds JS, Gutkin DW, Star A, Reiner RS, Halappanavar S, Kagan VE (2016) Gender differences in murine pulmonary responses elicited by 
cellulose nanocrystals. Part Fibre Toxicol 13:28. https:// doi.org/10.1186/s12989-016-0140-x

Souza SF, Mariano M, Reis D, Lombello CB, Ferreira M, Sain M (2018) Cell interactions and cytotoxic studies of cellulose nanofibers from Curauá natural fibers. Carbohydr Polym 201:87-95. https://doi.org/10.1016/j.carbpol.2018. 08.056

Stefaniak AB, Seehra MS, Fix NR, Leonard SS (2014) Lung biodurability and free radical production of cellulose nanomaterials. Inhal Toxicol 26:733-749. https://doi.org/ 10.3109/08958378.2014.948650

Sunasee R, Araoye E, Pyram D, Hemraz UD, Boluk Y, Ckless K (2015) Cellulose nanocrystal cationic derivative induces NLRP3 inflammasome-dependent IL-1 $\beta$ secretion associated with mitochondrial ROS production. Biochem Biophys Rep 4:1-9. https://doi.org/10.1016/j.bbrep.2015.08. 008

Takács E, Wojnárovits L, Földváry C, Hargittai P, Borsa J, Sajó I (2000) Effect of combined gamma-irradiation and alkali treatment on cotton-cellulose. Radiat Phys Chem 57:399-403. https://doi.org/10.1016/S0969806X(99)00409-0

Tavares AM, Louro H, Antunes S, Quarre S, Simar S, de Temmerman PJ, Verleysen E, Mast J, Jensen KA, Norppa H, Nesslany F, Silva MJ (2014) Genotoxicity evaluation of nanosized titanium dioxide, synthetic amorphous silica and multi-walled carbon nanotubes in human lymphocytes. Toxicol In Vitro 28:60-69. https://doi.org/10.1016/j.tiv. 2013.06.009

Tayeb A, Amini E, Ghasemi S, Tajvidi M (2018) Cellulose nanomaterials-binding properties and applications: a review. Molecules 23:2684

Thomas B, Raj MC, Joy J, Moores A, Drisko GL, Sanchez C (2018) Nanocellulose, a versatile green platform: from biosources to materials and their applications. Chem Rev 118:11575-11625

Tibolla H, Pelissari FM, Martins JT, Lanzoni EM, Vicente AA, Menegalli FC, Cunha RL (2019) Banana starch nanocomposite with cellulose nanofibers isolated from banana peel by enzymatic treatment: In vitro cytotoxicity assessment. Carbohydr Polym 207:169-179. https://doi. org/10.1016/j.carbpol.2018.11.079

Tibolla H, Pelissari FM, Menegalli FC (2014) Cellulose nanofibers produced from banana peel by chemical and enzymatic treatment. LWT Food Sci Technol 59:1311-1318

Tsukamoto J, Durán N, Tasic L (2013) Nanocellulose and bioethanol production from orange waste using isolated microorganisms. J Braz Chem Soc 24:1537-1543

Tuerxun D, Pulingam T, Nordin NI, Chen YW, Kamaldin JB, Julkapli NBM, Lee HV, Leo BF, Johan MRB (2019) Synthesis, characterization and cytotoxicity studies of nanocrystalline cellulose from the production waste of rubber-wood and kenaf-bast fibers. Eur Polym J 116:352-360. https://doi.org/10.1016/j.eurpolymj.2019. 04.021

Turbak AF, Snyder FW, Sandberg KR Microfibrillated cellulose, a new cellulose product: properties, uses, and commercial potential. In: J. Appl. Polym. Sci.: Appl. Polym. Symp.;(United States), 1983. vol CONF-8205234-Vol. 2. ITT Rayonier Inc., Shelton, WA,
Ureña-Benavides EE, Ao G, Davis VA, Kitchens CL (2011) Rheology and phase behavior of lyotropic cellulose nanocrystal suspensions. Macromolecules 44:8990-8998. https://doi.org/10.1021/ma201649f

Varshney V, Naithani S (2011) Chemical functionalization of cellulose derived from nonconventional sources. In: Cellulose fibers: Bio-and nano-polymer composites. Springer, pp 43-60

Vartiainen J, Pohler T, Sirola K, Pylkkanen L, Alenius H, Hokkinen J, Tapper U, Lahtinen P, Kapanen A, Putkisto K, Hiekkataipale P, Eronen P, Ruokolainen J, Laukkanen A (2011) Health and environmental safety aspects of friction grinding and spray drying of microfibrillated cellulose. Cellulose 18:775-786. https://doi.org/10.1007/s10570011-9501-7

Ventura C, Lourenco AF, Sousa-Uva A, Ferreira PJT, Silva MJ (2018) Evaluating the genotoxicity of cellulose nanofibrils in a co-culture of human lung epithelial cells and monocyte-derived macrophages. Toxicol Lett 291:173-183. https://doi.org/10.1016/j.toxlet.2018.04.013

Ventura C and Silva MJ (2017) Exposição ocupacional a nanofibras: abordagem in vitro dos efeitos genéticos e epigenéticos. 24-Mai-2017 ed. Comunidades \& Colecções, Departamento de Genética Humana, DGH - Palestras: Repositório Científico do Instituto Nacional de Saúde.

Ventura C, Sousa-Uva A, Lavinha J, Silva MJ (2018) Conventional and novel "omics"-based approaches to the study of carbon nanotubes pulmonary toxicity. Environ Mol Mutagen 59:334-362. https://doi.org/10.1002/em.22177

Wang J, Liu X, Jin T, He H, Liu L (2019) Preparation of nanocellulose and its potential in reinforced composites: a review. J Biomater Sci Polym Ed 30:919-946. https://doi. org/10.1080/09205063.2019.1612726

Xiao Y, Liu Y, Wang X, Li M, Lei H, Xu H (2019) Cellulose nanocrystals prepared from wheat bran: characterization and cytotoxicity assessment International. J Biol Macromol 140:225-233. https://doi.org/10.1016/j.ijbiomac. 2019.08.160

Yanamala N, Farcas MT, Hatfield MK, Kisin ER, Kagan VE, Geraci CL, Shvedova AA (2014) In vivo evaluation of the pulmonary toxicity of cellulose nanocrystals: a renewable and sustainable nanomaterial of the future. ACS Sustain Chem Eng 2:1691-1698. https://doi.org/10.1021/ sc500153k

Yanamala N, Kisin ER, Menas AL, Farcas MT, Khaliullin TO, Vogel UB, Shurin GV, Schwegler-Berry D, Fournier PM, Star A, Shvedova AA (2016) In vitro toxicity evaluation of lignin-(un)coated cellulose based nanomaterials on human A549 and THP-1 cells. Biomacromol 17:3464-3473. https://doi.org/10.1021/acs.biomac.6b00756

Yang X, Cranston ED (2014) Chemically cross-linked cellulose nanocrystal aerogels with shape recovery and superabsorbent properties. Chem Mater 26:6016-6025. https://doi. org/10.1021/cm502873c

Yoshida S, Hiyoshi K, Ichinose T, Takano H, Oshio S, Sugawara I, Takeda K, Shibamoto T (2009) Effect of nanoparticles on the male reproductive system of mice. Int J Androl 32:337-342. https://doi.org/10.1111/j.1365-2605. 2007.00865.x

Yu H, Qin Z, Liang B, Liu N, Zhou Z, Chen L (2013) Facile extraction of thermally stable cellulose nanocrystals with a 
high yield of $93 \%$ through hydrochloric acid hydrolysis under hydrothermal conditions. Journal of Materials Chemistry A 1:3938-3944. https://doi.org/10.1039/ C3TA01150J

Zhang Y, Chang P, Ma X, Lin N, Huang J (2019) Strategies to explore biomedical application of nanocellulose, pp 349-395. doi:10.1002/9783527807437.ch11

Zhao H-k, Wei X-y, Xie Y-m, Feng Q-h (2019) Preparation of nanocellulose and lignin-carbohydrate complex composite biological carriers and culture of heart coronary artery endothelial cells. Int J Biol Macromol 137:1161-1168. https://doi.org/10.1016/j.ijbiomac.2019.07.062

Zhou Y, Saito T, Bergström L, Isogai A (2018) Acid-free preparation of cellulose nanocrystals by TEMPO oxidation and subsequent cavitation. Biomacromol 19:633-639. https://doi.org/10.1021/acs.biomac.7b01730

Zhu H, Luo W, Ciesielki PN, Fang Z, Zhu JY, Henriksson G, Himmel ME, Hu L (2016) Wood-derived materials for green electronics, biological devices, and energy applications. Chem Rev 116:9305-9374. https://doi.org/10.1021/ acs.chemrev.6b00225

Zhu JY, Sabo R, Luo X (2011) Integrated production of nanofibrillated cellulose and cellulosic biofuel (ethanol) by enzymatic fractionation of wood fibers. Green Chem 13:1339-1344. https://doi.org/10.1039/C1GC15103G

Zhu W, Zhu JY, Gleisner R, Pan XJ (2010) On energy consumption for size-reduction and yields from subsequent enzymatic saccharification of pretreated lodgepole pine. Biores Technol 101:2782-2792. https://doi.org/10.1016/j. biortech.2009.10.076

Publisher's Note Springer Nature remains neutral with regard to jurisdictional claims in published maps and institutional affiliations. 